\title{
Kaiserkritik und Gotenbild im Geschichtswerk des Malchos von Philadelpheia ${ }^{1}$
}

\author{
HANS-UlRich WIEMER
}

I.

Das öffentliche Bild des Kaisers Anastasius wurde für viele Jahre durch ein Thema bestimmt: den Kampf gegen die Isaurer. Anastasius hatte den isaurischen Gefolgsleuten seines Vorgängers Zenon gleich nach seinem Regierungsantritt am 11. April 491 den Kampf angesagt. ${ }^{2}$ Zenons Bruder Longinus mußte in die Verbannung gehen und ebenso der gleichnamige magister officiorum $;^{3}$ das jährliche Donativ für die Isaurer wurde gestrichen, ihr Vermögen in der Hauptstadt konfisziert. ${ }^{4}$ Die Isaurer traten in den Aufstand, und es dauerte sieben Jahre, bis sie endgültig besiegt waren. ${ }^{5}$ Der Sieg wurde als

1 Ich danke Andreas Goltz für die Diskussion auf der Lindheimer Tagung, Wolfram Brandes und Hartmut Leppin für Hinweise zur verschriftlichten Fassung, Daniel Kah und Oliver Hihn für die gründliche Korrektur des Manuskripts.

2 Eine befriedigende moderne Monographie über Kaiser Zenon fehlt. Nach wie vor unentbehrlich sind der klassische Aufsatz von E. W. Brooks, The Emperor Zenon and the Isaurians, EHR 30, 1893, 209-238, das Kapitel bei E. Stein, Histoire du BasEmpire, Bd. 2: De la disparition de l'empire d'Occident à la mort de Justinien, Paris u. a. 1949, 7-76 sowie der RE-Artikel von A. Lippold, Zenon 17, RE XA, 1972, 149-213. Einen informativen Überblick zur Quellenlage bietet A. Laniado, Some Problems in the Sources for the Reign of the Emperor Zeno, BMGS 15, 1991, $147-$ 173. Bei K. Feld, Barbarische Bürger. Die Isaurier und das Römische Reich (Millenium-Studien 8), Berlin 2005, 207-338 finden sich leider viele Mißverständnisse und Fehler; vgl. dazu die Rezension von T. Schmitt, H-Soz-u-Kult, 22.01.2007, http:// hsozkult.geschichte.hu-berlin.de/rezensionen/2007-1-047.

3 Zenons Bruder (PLRE II Longinus 6) wurde nach Ägypten verbannt und starb dort sieben oder acht Jahre später: Joh. Ant. F 214b Müller = F 308 Roberto, Z. 26-28; Theoph. AM 5984; Zon. 14, 3, 20. Zenons magister officiorum floh nach Isaurien und war einer der Anführer der Rebellion gegen Anastasius, bis er 497 in Gefangenschaft geriet und hingerichtet wurde: PLRE II Longinus 3.

4 Joh. Ant. F 214b Müller = F 308 Roberto, Z. 35-39; Eustath. F $6=$ Euagr. 3, 35; Jord. Rom. 354.

5 Zum Isaurerkrieg des Anastasius vgl. Brooks (s. Anm. 2), 231-238; C. Capizzi, L'imperatore Anastasio I (491-518). Studio sulla sua vita, la sua opera e la sua personalità (OCA 184), Rom 1969, 89-99; F. Haarer, Anastasius I. Politics and Empire in the Late Roman World, Leeds 2006, 11-28. 
Triumph über wilde Barbaren inszeniert, die selbst dem großen Pompeius getrotzt hatten und nun, ein halbes Jahrtausend später, erstmals unterworfen wurden. ${ }^{6} 497$ präsentierte Anastasius dem jubelnden Volk Konstantinopels im Hippodrom die abgetrennten Köpfe zweier isaurischer Anführer, die er anschließend öffentlich ausstellen ließ. ${ }^{7}$ Im Jahr darauf, als der letzte Widerstand gebrochen war, ließ er zwei weitere Anführer in Ketten durch die Straßen Konstantinopels treiben und gab sie im Hippodrom dem Spott und Hohn der Zuschauer preis, bevor sie in Nikaia hingerichtet wurden. ${ }^{8}$

Aber die Botschaft wurde auch durch andere Medien verbreitet. An der Chalke, dem monumentalen Torbau am Eingang zum Kaiserpalast, wurde ein Epigramm angebracht, in welchem Anastasius als Tyrannentöter gerühmt wurde, weil er die Isaurer erschlagen habe. ${ }^{9}$ Die Panegyristen haben das Thema willig aufgegriffen. Der in Konstantinopel tätige lateinische grammaticus Priscian verherrlichte Anastasius in einem Panegyricus in Versen als Bezwinger der Isaurer. ${ }^{10}$ In der Provinz wollte man dahinter nicht zurückstehen: Als der Rhetoriklehrer Prokopios in seiner Heimatstadt Gaza den Ruhm des regie-

6 Priscian. Pan. 15-18: sed tamen egregio, Pompei, cede nepoti | namque genus, quod tu, terrarum victor ubique $\mid$ indomitum Tauri linquebas collibus altis $\mid$ his domuit penitus convellens semina belli; Anth. Graec. 2, 398-406.

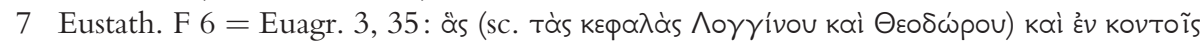

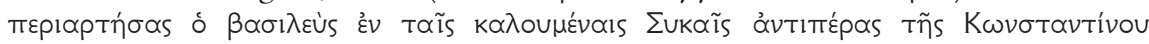

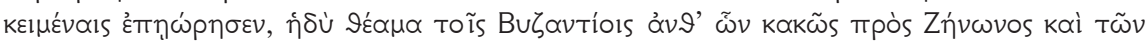

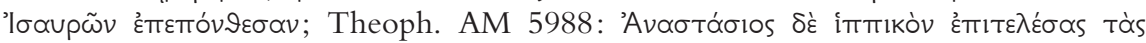

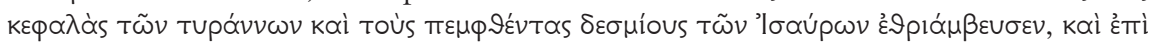

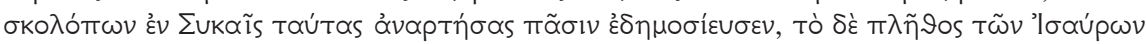

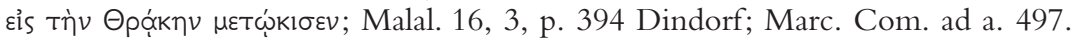

8 Priscian. Pan. 171-173: ipse locus vobis ostendit iure tropaea | obtulit et vinctos oculis domitosque tyrannos $\mid$ ante pedes vestros mediis circensibus actos; Eustath. F $6=$ Euagr. 3, 35: ò

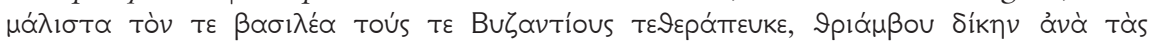

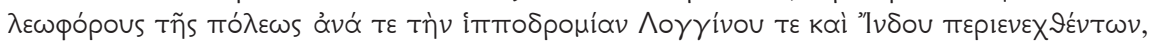

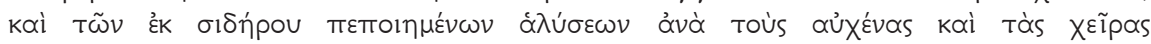

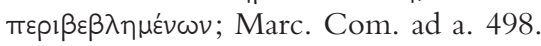

9 Anth. Pal. 9, 656.

10 Priscian. Pan. 10-129. Quellen und Literatur zu Leben und Werken bei R. A. Kaster, Guardians of Language. The Grammarian and Society in Late Antiquity, Berkeley u.a. 1988, 346-348 Nr. 126. Das genaue Abfassungsdatum ist im vorliegenden Zusammenhang unerheblich; während sich nach A. Chauvot, Procope, Priscien de Cesarée. Panegyriques de l'empereur Anastase Ier. Textes traduites et commentés, Bonn 1986, 98-107, dessen Ausgabe ich benutze, auch P. Coyne, Priscian of Caesarea's De Laude Anastasii imperatoris, Lampeter 1991, 7-16 für eine Datierung auf das Jahr 513 ausgesprochen hat, tritt Haarer (s. Anm. 5), 272-277 erneut für den von Alan Cameron, The Date of Priscian's De Laude Anastasii, GRBS 15, 1974, 313-316 vorgeschlagenen Ansatz auf das Jahr 502 ein. Das literarische Umfeld skizziert F. K. Nicks (= Haarer), Literary Culture in the Reign of Anastasius, in: S. Mitchell/G. Greatrex (Hgg.), Ethnicity and Culture in Late Antiquity, Swansea 2000, 183-203. 
renden Kaisers verkündete, verfehlte er nicht, den Sieg über die isaurischen Barbaren gebührend hervorzuheben. ${ }^{11}$ Auch Dichter nahmen sich des Themas an; hier tat sich namentlich Christodoros von Koptos hervor, der ein Epos mit dem Titel „Isaurika“ verfaßte. ${ }^{12}$

Der Bruch, den Anastasius mit dem Regime seines Vorgängers vollzog, war jedoch keineswegs vollständig. Die dynastische Kontinuität war gewahrt, denn Ariadne, die Witwe Zenons, stand bis 515 als Augusta an Anastasius' Seite. Aber auch politisch setzte Anastasius in mancher Hinsicht fort, was Zenon begonnen hatte. Dies gilt namentlich für die Gotenpolitik. Anastasius hätte nicht so entschieden gegen die Isaurer vorgehen können, wenn es Zenon nicht zuvor gelungen wäre, den größten gotischen Kriegerverband aus dem Balkan zu entfernen, indem er dessen Anführer Theoderich, den Sohn des Thiudimir, mit der Aufgabe betraute, die Herrschaft Odovakars in Italien zu beenden und dort an Kaisers Statt zu herrschen, bis dieser selbst nach Italien komme. Anastasius hat Theoderichs Stellung als König in Italien nach anfänglichem Zögern anerkannt und, von kurzen Störungen abgesehen, bis zum Ende seiner Herrschaft gute Beziehungen $\mathrm{zu}$ ihm unterhalten. ${ }^{13}$

Weil Zenon auch nach seinem Tod als legitimer Kaiser anerkannt war, haben Redner, die das Wort ergriffen, um Anastasius zu loben, es tunlichst vermieden, Zenon beim Namen zu nennen, wenn sie die Segnungen des neuen Zeitalters priesen, indem sie überwundene Übel schilderten. Prokopios erinnerte seine Hörer daran, daß man bis zu Anastasius' Regierungsantritt seines Wohlstandes nicht froh geworden sei, weil man dauernd von falschen Anklagen bedroht gewesen sei, die viele Reiche an den Bettelstab gebracht hätten. ${ }^{14}$ Zenons Name fiel dabei nicht. Priscian sprach davon, daß Anastasius die Welt von der Gewaltherrschaft eines Volkes (genus) befreit habe, das die Gesetze mißachtet und in seiner Habgier auch die Armen nicht verschont habe. ${ }^{15}$ Früher seien die Ämter an Unwürdige verkauft worden, die sich ih-

11 Proc. Pan. 8-10. Zur Datierung auf das Jahr 502 vgl. Chauvot (s. Anm. 10), 95-97, dem G. Matina, Panegirico per l'imperatore Anastasio. Introduzione, testo critico, traduzione e commento (Quaderni dell'Accademia pontania 41), Neapel 2005, 28-29 folgt.

12 Christodoros' „Isaurika“ sind zwar lediglich dem Titel nach bekannt, doch läßt sich ihre Tendenz aus seinem Gedicht auf die Statuen im Zeuxippos-Gymnasium mühelos erschließen: Anth. Pal. 2, bes. 405-406. Über die „Isaurika“ des Lykiers Capito läßt sich kaum etwas aussagen, weil das Werk fast nur für Ortsnamen zitiert worden ist (FHG IV, 133-134). Immerhin ist durch F $5=$ Steph. Byz. s. v. Yima $₫ \alpha$ gesichert, daß er den Isaurerkrieg des Anastasius behandelt hat.

13 Zur Gotenpolitik des Anastasius vgl. Capizzi (s. Anm. 5), 157-173; J. Prostko-Prostynski, Utraeque res publicae. The Emperor Anastasius I's Gothic Policy (491-518), Posen 1994; Haarer (s. Anm. 5), 73-103.

14 Proc. Pan. 5.

15 Priscian. Pan. 20-37. 
rerseits auf Kosten der Untertanen bereichert hätten. Auch das habe unter Anastasius nun endlich ein Ende, versicherten die Panegyristen. ${ }^{16}$ Und natürlich rühmte man die Außenpolitik des Anastasius: Er weise die Barbaren in die Schranken und gewähre dadurch den Städten des Ostens den Schutz vor Plünderungen, den sie so lange entbehrt hätten. ${ }^{17}$ Auf die Goten ging Priscian nicht ein, wenngleich er die Hoffnung aussprach, daß beide Städte namens Rom allein Anastasius gehorchen mögen. ${ }^{18}$

Autoren, die unter Anastasius Werke historiographischen Charakters verfaßten, ${ }^{19}$ sind mit Zenon weniger taktvoll umgegangen, haben seine Regierung darum aber keineswegs nach einem einheitlichen Muster dargestellt. Eustathios von Epiphaneia, der vermutlich unter Anastasius eine „Weltchronik" verfaßte, die von Adam bis zum Jahre 502 reichte, ${ }^{20}$ hat Zenon sehr negativ beurteilt und auch persönlich heftig angegriffen. Insbesondere lastete er ihm die Verantwortung für die Rebellion des Illus an, da der Kaiser Intrigen gegen seine Schwiegermutter Verina gesponnen und seinem Heermeister nach dem Leben getrachtet habe. Eustathios warf Zenon Grausamkeit und Verrat vor und sah in diesen Eigenschaften den Grund, weshalb Theoderich, der zwar der Abstammung nach Gote, aber auch bei den Römern angesehen

16 Proc. Pan. 7; Priscian. Pan. 195-203, bes. 201-202: aurum non adhibes, moderantes ante solebant $\mid$ quod dare, ne liceat socios evertere furtis.

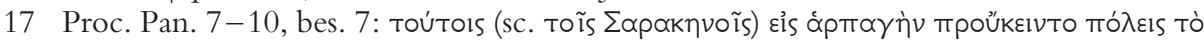

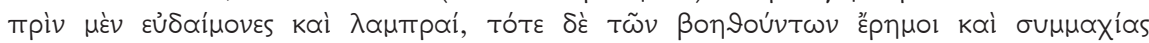

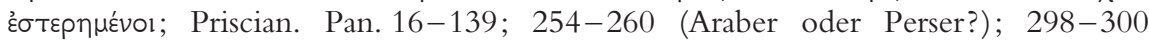
(,Skythen“" und „Parther").

18 Priscian. Pan. 265: utraque Roma tibi nam spero pareat uni.

19 Vgl. dazu die Beiträge von R. C. Blockley (,,The Development of Greek Historiography: Priscus, Malchus and Candidus“), M. R. Cataudella (,Historiography in the East") und Michael Whitby (,The Church Historians and Chalcedon“) in dem von G. Marasco herausgegebenen Handbuch Greek and Roman Historiography in Late Antiquity. Fourth to Sixth Century A.D., Leiden 2003 sowie W. Treadgold, The Early Byzantine Historians, Basingstoke - New York 2007 (mit der berechtigten Kritik von D. Brodka, H-Soz-u-Kult, 20.08.2007, http://hsozkult.geschichte.hu-berlin.de/rezensionen/2007-3-130).

20 Die sieben unter Eustathios' Namen zitierten Fragmente stehen in FHG IV, 138-142; alle bis auf eines (F 7 = Malal. 16, 9, p. 398) stammen aus Euagrios. F $2=$ Euagr. 2, 15 zeigt, daß Eustathios den Aufstieg Zenons ausführlich behandelt hat. F $3=$ Euagr. 3, 25 belegt sein Interesse für die Auseinandersetzung Zenons mit den gotischen Anführern. Ein neues Fragment aus dem ansonsten vollständig verlorenen ersten Teil des Werkes, der wohl mit Adam begann und bis zum Trojanischen Krieg führte, ediert und kommentiert P. Allen, An Early Epitomator of Josephus. Eustathius of Epiphaneia, BZ 81, 1988, 1-11. Eine eingehende Studie zu Eustathios fehlt bislang; einen Teilaspekt behandelt D. Brodka, Eustathios von Epiphaneia und das Ende des Weströmischen Reiches, JÖB 56, 2006, 59-78, dessen Beweisführung gegen die traditionelle Annahme, daß Euagrios $(2,16)$ das Epochenjahr 476 bei Eustathios fand, mir jedoch nicht schlüssig erscheint. 
gewesen sei, sich in das alte Rom zurückgezogen habe. ${ }^{21}$ Wenn der Bericht des Theophanes über Theoderich auf dieselbe Quelle zurückgeht, hat Eustathios dem gotischen König Tapferkeit und Klugheit, ja sogar griechische Bildung zugeschrieben. ${ }^{22}$ In den Jubel der Einwohner Konstantinopels beim Anblick gefangener oder getöteter Isaurer stimmte Eustathios ein. ${ }^{23}$

Bei dem Isaurer Candidus, der die Geschichte der Kaiser Leon und Zenon aus einer isaurischen Perspektive darstellte, kam Zenon ebenfalls nicht gut weg. ${ }^{24}$ Candidus, der führenden Isaurern als Sekretär gedient hatte, hielt es mit Zenons Landsmann Illus, der seiner Darstellung zufolge von Zenon durch eine Serie von Mordanschlägen in die Usurpation getrieben worden war. ${ }^{25}$ Candidus verteidigte Illus als treuen Diener des Reiches, ${ }^{26}$ der gegen seinen Willen zum Usurpator geworden sei, und als frommen Anhänger der Synode von Chalkedon, der als Zeuge des wahren Glaubens gestorben sei. ${ }^{27}$ Er ging auch ausführlich auf die beiden gotischen Anführer mit Namen Theoderich ein,

21 Eustath. F 4 = Euagr. 3, 27.

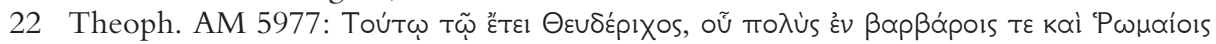

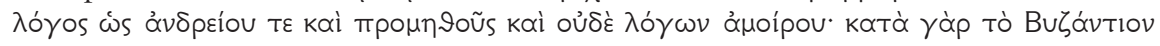

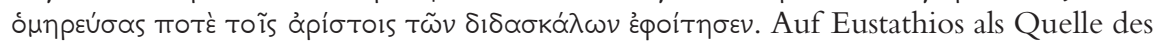
Theophanes, der seinerseits Nikephoros Kallistos Xanthopoulos (H. E. 16, 23, PG 147, 157D-160B) als Vorlage gedient hat (vgl. G. Gentz, Die Kirchengeschichte des Nicephorus Callistus Xanthopulus und ihre Quellen. Nachgelassene Untersuchungen. Überarbeitet und erweitert von F. Winkelmann (TU 98), Berlin-Ost 1966, 158), weist freilich allein die inhaltliche Nähe zu Euagr. 3, 27.

23 Eustath. F $6=$ Euagr. 3, 35, zitiert oben Anm. $7+8$.

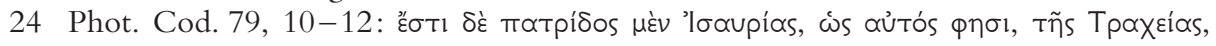

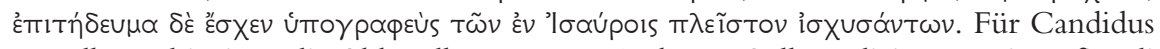
grundlegend ist jetzt die Abhandlung von U. Roberto, Sulla tradizione storiografica di Candido Isauro, Mediterraneo antico 3, 2000, 685-727, der gute Argumente für die bereits von A. Köcher, De Johannis Antiocheni aetate fontibus auctoritate, Diss. Bonn 1871 vertretene These vorbringt, daß Johannes Antiochenus Candidus als Hauptquelle für die Geschichte Zenons und der Isaurer (F 210-214a Müller = F 302-307 Roberto) benutzt hat.

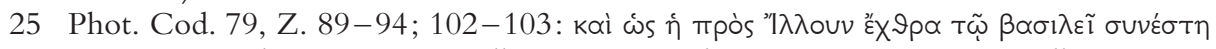

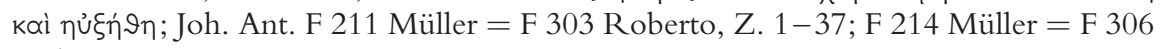
Roberto, Z. 1-5.

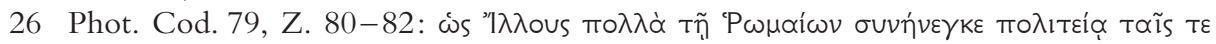

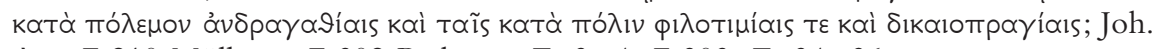
Ant. F 210 Müller = F 302 Roberto, Z. 3-4; F 303, Z. 34-36.

27 Joh. Ant. F 214 Müller = F 306 Roberto, Z. 44 ff., bes. 50-51; 61-64; 70-71; 90100. Candidus machte vor allem den Heiden Pamprepius für die Katastrophe des Illus verantwortlich: Phot. Cod. 79, Z. 94-96; Joh. Ant. F 211 Müller = F 303 Roberto, Z. $25-29 ; 36-37$. 
von denen der eine seiner Darstellung zufolge ebenso gewalttätig und eidbrüchig war wie der andere. ${ }^{28}$

Der Verfasser der syrischen Chronik hingegen, die unter dem Namen Josua Stylites bekannt ist, ${ }^{29}$ stand Zenon erheblich positiver gegenüber. Er stellte zwar fest, daß Zenon seine Landsleute protegiert habe und deshalb von den Römern gehaßt worden sei, ${ }^{30}$ rechtfertigte sein Vorgehen gegen Illus jedoch, indem er wiederholt feststellte, der Kaiser habe gewußt, daß Illus das Kaisertum für sich selbst erstrebt habe. ${ }^{31}$ Der anti-chalkedonische Theologe Zacharias von Mytilene schließlich, dessen in griechischer Sprache verfaßte „Kirchengeschichte“ lediglich in einer verkürzten Übersetzung ins Syrische überliefert ist, ${ }^{32}$ hat die Kaiser allein nach ihrer Religionspolitik beurteilt. Da

28 Joh. Ant. F 210 Müller = F 302 Roberto, Z. 1-3 (Strabo erschlägt den Heermeister

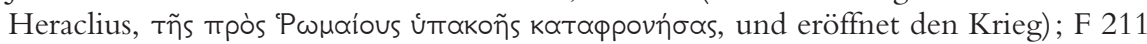
Müller = F 303 Roberto, Z. 76-91 (Strabo verbündet sich mit den Hunnen, zieht

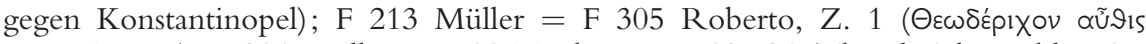

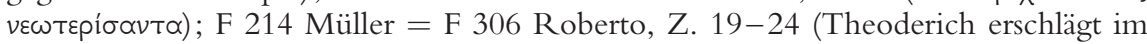

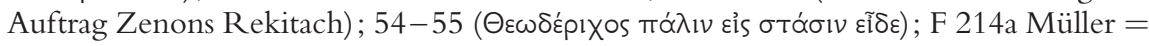
F 307 Roberto (Theoderich bricht seinen Eid und ermordet Odovakar).

29 Ich zitiere die Übersetzung von A. Luther, Die syrische Chronik des Josua Stylites (UaLG 49), Berlin - New York 1997. Die englische Übersetzung: The Chronicle of Pseudo-Joshua the Stylite. Translated with Notes and Introduction by F. R. Trombley and J. W. Watt, Liverpool 2000 wurde verglichen. Der syrische Text findet sich bei: W. Wright, The Chronicle of Joshua the Stylite Composed in Syriac A.D. 507 with a Translation into English and Notes, Cambridge 1882.

30 Jos. Styl. 12: „Die Angehörigen des Palastes haßten nämlich den Kaiser Zeno, weil er seiner Abstammung nach Isaurier war. ... Er hatte als Vertrauensmann in dieser Sache den Feldherrn von Antiochien, dessen Name Illus war und der Isaurier war. An alle Angehörigen seines Volkes gab er nämlich Ehren- und Amtsstellen, und aufgrund dessen wurde er von den Römern noch mehr gehaßt“; 14: „Allein konnte er (sc. Illus) nämlich nicht rebellieren und auch nicht selbst herrschen, da auch ihn die Römer aufgrund seiner Abstammung und wegen seines harten Sinnes haßten."

31 Jos. Styl. 12-17, bes. 13: „Da Zeno aber wußte, daß (sc. Illus) ein Betrüger war und begierig auf die Herrschaft, befahl er einem Diener, ihn zu töten“; 14: „Weil sich nun Zeno vor Illus fürchtete (er kannte nämlich seine Schlechtigkeit)..."

32 Die englische Übersetzung von F. J. Hamilton/E. W. Brooks, The Syriac Chronicle Known as that of Zachariah of Mytilene, London 1899 ist zuverlässiger als K. Ahrens/ G. Krüger, Die sogenannte Kirchengeschichte des Zacharias Rhetor in deutscher Übersetzung, Leipzig 1899 (vgl. dazu die kritische Besprechung durch M.-A. Kugener, La compilation historique de Pseudo-Zacharie le Rhéteur, ROC 5, 1900, 201-214; $461-480)$. Brooks hat später auch die maßgebliche Ausgabe des syrischen Texts besorgt, die von einer lateinischen Übersetzung begleitet wird: Historia ecclesiastica Zachariae Rhetori vulgo adscripta. Edidit et interpretatus est E. W. Brooks (CSCO 83/ $84+87 / 88)$, 4 Bde., Louvain 1919-1924. Über Leben und Werke des Zacharias Rhetor vgl. E. Honigmann, Zacharias of Mytilene (536 A. D.), in: ders., Patristic Studies XXI (StT 173), Vatikanstadt 1953, 194-204; M. Minniti Colonna, Zacaria Scolastico. Ammonio. Introduzione, testo critico, traduzione, commentario, Neapel 
er ein Gegner der Synode von Chalkedon war, schilderte er den Usurpator Basiliskos, der sich - anders als Zenon - offen gegen deren Beschlüsse erklärt hatte, mit merklicher Sympathie. ${ }^{33}$ Dagegen war Illus als Anhänger der Zweinaturenlehre für Zacharias natürlich ein Tyrann. ${ }^{34}$ Mit Zenons „Henotikon" war Zacharias einverstanden, weil es sich anti-chalkedonisch interpretieren ließ. ${ }^{35}$ Da Zenon prominente Gegner der Synode wie Petros Mongos oder Petros den Walker wieder in ihre Bistümer hatte zurückkehren lassen, stand seine Legitimität außer Frage. ${ }^{36}$

Die „Byzantinische Geschichte“ des Malchos, ${ }^{37}$ die den Gegenstand der folgenden Ausführungen bildet, ist vor diesem Hintergrund zu interpretieren. Denn Malchos hat sein Werk aller Wahrscheinlichkeit nach ebenfalls unter Anastasius verfaßt, wenngleich sich das genaue Datum nicht bestimmen läßt. ${ }^{38}$

1973, 15 ff.; speziell zur Kirchengeschichte des Zacharias vgl. J. Rist, Die sogenannte Kirchengeschichte des Zacharias Rhetor: Überlieferung, Inhalt und theologische Bedeutung, in: M. Tamcke (Hg.), Syriaca. Zur Geschichte, Theologie, Liturgie und Gegenwartslage der syrischen Kirchen. 2. Deutsches Syrologensymposium (Juli 2000, Wittenberg), Münster u.a. 2002, 77-99; Michael Whitby bei Marasco (s. Anm. 19), 459-466 sowie jetzt vor allem P. Blaudeau, Alexandrie et Constantinople (451-491). De l'histoire à la géo-ecclésiologie (Bibliothèque des Écoles Françaises d'Athènes et de Rome 327), Rom 2006, 493-617, bes. $581 \mathrm{ff}$.

33 Zach. Rhet. H. E. 5, 1-3. Basiliskos wird wiederholt als Kaiser bezeichnet.

34 Zach. Rhet. H. E. 5, 6: Illus steht im Bunde mit Johannes „dem Lügner“, dem chalkedonischen Patriarchen Alexandreias; 5, 9: Illus, Leontius und Pamprepius Rebellen. In der „Vita Isaiae“ wird Illus nachgesagt, er sei unter dem Einfluß des Pamprepius zum Heidentum abgefallen (ed. Brooks, CSCO 8, p. 7). Derselbe Vorwurf begegnet auch in der „Vita Severi“ (ed. Kugener, PO 2, 1, p. 40).

35 Zach. Rhet. H. E. 5, 7-8; 10-12; 6, 5-6.

36 Zach. Rhet. H. E. 5, 7 (Petros Mongos) bzw. 9 (Petros der Walker). Im „Totengericht" über Zenon $(6,6)$ wird dessen Legitimität betont, doch könnte dieser Abschnitt auch vom Bearbeiter stammen. In der „Vita Severi“ (p. 40 Kugener) wird Zenon mit dem Zusatz „seligen Angedenkens“ genannt (mißverstanden von Feld [s. Anm. 2], 281); in der „Vita Isaiae“ (p. 7 Brooks) mit dem Zusatz qui vitam religiose finivit.

37 Ich zitiere Malchos nach der grundlegenden Ausgabe von L. R. Cresci, Malco di Filadelfia, Frammenti. Testo critico, introduzione, traduzione e commentario (Byzantina et Neo-Hellenica Neapolitana 9), Neapel 1982, deren Zählung mit derjenigen Karl Müllers in den „Fragmenta Historicorum Graecorum“ (Bd. 4, Paris 1868, $111-$ 133) und Ludwig Dindorfs in den „Historici Graeci Minores“ (Bd. 1, Leipzig 1870, 383-424) übereinstimmt. R. C. Blockley, The Fragmentary Classicising Historians of the Later Roman Empire. Eunapius, Olympiodorus, Priscus and Malchus, Bd. 1, Liverpool 1981 hat ebenfalls auf diese Zählung verwiesen, in seiner Ausgabe dann aber eine neue Zählung eingeführt (Bd. 2: Text, Translation and Historiographical Notes, Liverpool 1983, 402-473), die nur über die Konkordanz zu entschlüsseln ist. Die Abkürzungen ELR und ELG verweisen auf die „Excerpta de legationibus Romanorum“ und auf die „Excerpta de legationibus gentium ad Romanos“" (ed. C. de Boor, 2 Bde., Berlin 1903-1905).

38 Nach dem Suda-Artikel $=$ T 1 reichte das Werk von Konstantin I. bis Anastasius. Man kann nicht ausschließen, daß Malchos zu schreiben begann, während Zenon noch lebte 
Wenn wir der „Suda“ trauen dürfen, begann das Werk mit der Gründung Konstantinopels und reichte bis zum Regierungsantritt des Anastasius; das ergibt einen terminus post quem. Die Überlieferungslage macht es schwierig, Aussagen über den Aufbau, den Umfang und die Verteilung des behandelten Stoffs zu machen: Malchos' Werk wurde offenbar nur wenig gelesen und lag schon um die Mitte des 9. Jahrhunderts nur noch in einer am Anfang und am Ende verstümmelten Version vor; jedenfalls enthielt das Exemplar, aus dem sich der unersättliche Photios einen Auszug anfertigte, nur die Darstellung der Jahre 473 bis $480 .{ }^{39}$ Auch die Kommissionen, die etwa ein Jahrhundert später im Auftrag des Kaisers Konstantinos VII. Porphyrogennetos daran gingen, aus den damals noch vorhandenen Geschichtswerken griechischer Sprache Exzerpte anzufertigen, um sie einer in 53 Abteilungen gegliederten Enzyklopädie einzufügen, hat keinen vollständigen Text mehr auftreiben können; alle Exzerpte stammen aus denselben sieben Büchern, die auch schon Photios gelesen hatte. Spätestens jetzt, nachdem die verstümmelte Version exzerpiert worden war, ging das Original ganz verloren. ${ }^{40}$

Der Versuch, den Geschichtsschreiber Malchos zu fassen, stößt also auf erhebliche Schwierigkeiten. Sein Werk ist im Original unwiederbringlich verloren und kann nur anhand von Exzerpten, Zitaten und Paraphrasen rekonstruiert werden. Eine indirekte Überlieferung wie diese wirft vielerlei Probleme auf: Die Tatsache, daß die als Exzerpt überlieferten Textpassagen

(vermutet von B. Baldwin, Malchus of Philadelphia, DOP 31, 1977, 91-107, hier: 91); da eine Publikation zu dessen Lebzeiten jedoch gefährlich gewesen wäre, ist das wenig wahrscheinlich. K. Martin, Theoderich der Große bis zur Eroberung Italiens,

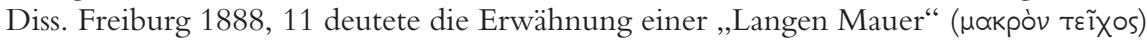
in F 16 = ELG 6, Z. 47 als anachronistischen Verweis auf die „Langen Mauern“ Konstantinopels (so auch noch Baldwin, 106), die seiner Ansicht erst unter Anastasius errichtet wurden. Diese Deutung wirkt gekünstelt und krankt auch daran, daß die „Langen Mauern“ wohl schon lange vor Anastasius existierten: so L. Michael Whitby, The Long Walls of Constantinople, Byz 55, 1985, 560-583 gegen B. Croke, The Date of the „Anastasian Long Wall“ in Thrace, GRBS 23, 1982, 59-78. Als terminus post quem für Malchos' Geschichtswerk sind die „Langen Mauern“ daher ungeeignet: R. Laqueur, Malchos 2, RE XIV, 1928, 851-857, hier: 851; Blockley (s. Anm. 37), I, 72; Cresci (s. Anm. 37), 22.

39 Phot. Cod. $78=$ T 2. Das siebte Buch endete nach Aussage des Photios mit dem Tode des Iulius Nepos. Photios zog daraus den Schluß, daß der Autor über seinem Werk verstorben sei. Das erste ihm vorliegende Buch muß abrupt begonnen haben, denn er meinte, den sieben erhaltenen Büchern ( $\lambda$ ó $\gamma \circ$ l) müßten andere vorhergegangen sein.

40 Auch Zonaras 14, 2 ( = F 7a) zitiert wohl aus der verkürzten Version. In einem Scholion zur Kirchengeschichte des Euagrios (ed. Bidez/Parmentier, 244 zu 123, Z. 5) wird darauf verwiesen, daß Malchos die Erhebung Markians beschrieben habe; auch dieser Verweis setzt keine Kenntnis des vollständigen Werks voraus. Schließlich bezieht sich auch die vermutlich Malchos entlehnte Beschreibung des Todes Kaiser Leons, die wir bei Kedrenos I, p. 614, Z. 18-615, Z. 2 Bekker (=F 2d) lesen, auf den Teil von Malchos' Werk, der Photios bekannt war; dessen Exzerpt setzt gerade damit ein. 
nach speziellen Kriterien ausgewählt wurden und daher keineswegs typisch für die Thematik des Gesamtwerks zu sein brauchen, ist wohl das gravierendste unter ihnen. Da uns nur wenige Abteilungen der konstantinischen Enzyklopädie überliefert sind, ${ }^{41}$ sind Gesandtschaften in den wörtlichen Fragmenten frühbyzantinischer Geschichtsschreiber in der Regel stark überrepräsentiert. Im Falle des Malchos dominieren sie die Überlieferung sogar vollkommen: Alle Exzerpte stammen aus den Sammlungen über Gesandtschaften der Römer an die Barbaren und über solche der Barbaren an die Römer; in ihrer großen Mehrzahl behandeln sie die Beziehungen zwischen den oströmischen Kaisern Leon und Zenon und den beiden gotischen Heerführern namens Theoderich. Bei Malchos kommt noch eine zusätzliche Schwierigkeit hinzu, weil so gut wie alle Reste seines Werkes eben aus einer verstümmelten Fassung stammen; erhebliche Teile seiner Darstellung haben daher überhaupt keine Spuren hinterlassen, weder in der konstantinischen Enzyklopädie, aus der auch die Suda geschöpft hat, ${ }^{42}$ noch im Auszug des Photios.

Gleichwohl ist der Versuch, einige Grundzüge der Geschichtsschreibung des Malchos zu ermitteln, nicht aussichtslos. $\mathrm{Zu}$ diesem vorsichtigen Optimismus berechtigt neben der Tatsache, daß die wörtlichen Zitate teilweise recht lang sind - das längste umfaßt in der Ausgabe von Lia Raffaella Cresci immerhin 320 Zeilen -, auch der Umstand, daß der exklusiv auf Diplomatie, insbesondere das Gotenproblem, gerichtete Fokus der konstantinischen Exzerpte bis zu einem gewissen Grade durch Passagen der "Suda“ komplementiert wird, die sich auf innere Angelegenheiten beziehen und mit hinreichender Wahrscheinlichkeit auf Malchos zurückgeführt werden können. ${ }^{43}$ Zudem hat Malchos die Zeit vor dem Regierungsantritt Zenons of-

41 Th. Büttner-Wobst, Die Anlage der historischen Enzyklopädie des Konstantinos Porphyrogennetos, BZ 15, 1906, 88-120; P. Schreiner, Die Historikerhandschrift Vaticanus Graecus 977: ein Handexemplar zur Vorbereitung des Konstantinischen Exzerptenwerkes?, JÖB 37, 1987, 1-29.

42 Den Nachweis erbrachte C. de Boor, Suidas und die konstantinische Exzerptsammlung, BZ 21, 1912, 381-424; BZ 23, 1914, 1-127.

43 Die Zuweisung von Suda-Artikeln an Malchos ist nur in wenigen Fällen durch ein namentliches Zitat gesichert; aus diesem Grund ist Blockley in seiner Ausgabe erheblich zurückhaltender als Cresci, wenn es darum geht, die Autorschaft anonymer Fragmente zu bestimmen (zum Problem vgl. Baldwin [s. Anm. 38], 98-101; Cresci [s. Anm. 37], 56-58). Da indessen bereits der Kompilator der Suda seine Kenntnis der Historiographen aus der konstantinischen Enzyklopädie schöpfte, hat die Annahme, daß Informationen der Suda, die sich auf die Regierung Leons und Zenons beziehen, auf Malchos zurückgehen, einen recht hohen Grad von Wahrscheinlichkeit für sich, denn im Gegensatz zu allen anderen historischen Werken, in denen diese Zeit ausführlich behandelt wurde, ist sein Werk nachweislich sowohl für die Enzyklopädie exzerpiert als auch in der Suda namentlich zitiert worden. Zwingend ist dieses Ar- 
fenbar knapp dargestellt, so daß der Textverlust wenigstens zum Teil Passagen betreffen dürfte, die eher einleitenden Charakter hatten. ${ }^{44}$

Im folgenden sollen zunächst das Gesellschaftsbild und das Kaiserideal des Malchos herausgearbeitet werden, um dann in einem zweiten Schritt zu betrachten, wie er die Gotenpolitik des Kaisers Zenon dargestellt hat. Dabei ist keine Rekonstruktion der Ereignisse beabsichtigt, die seit Edward Gibbon immer wieder nach Malchos erzählt worden sind. ${ }^{45}$ Gegenstand der Untersuchung sind die Kriterien, an denen er kaiserliches Handeln maß, und die literarischen Formen, deren er sich zu seiner Darstellung bediente. Es geht also um seine literarische Technik und um die Maßstäbe seiner Kaiserkritik, denn für Malchos wie für alle seine Zeitgenossen war der Kaiser für das Wohl des Reiches persönlich verantwortlich. ${ }^{46}$ Durch eine genauere literarische und historische Kontextualisierung kann man hier wohl noch etwas weiter kommen, als dies bisher gelungen ist. ${ }^{47}$ Auch wenn die 1928 getroffene Feststellung des Gießener Althistorikers Richard Laqueur, Spezialliteratur über Malchos sei

gument aber nicht, weil uns nur geringe Reste der Enzyklopädie erhalten sind und die Suda auch aus einigen verlorenen Abteilungen geschöpft hat. Ein namentliches Zitat

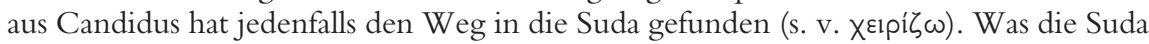
ohne Quellenangabe über den Isaurer Indacus mitzuteilen weiß, fließt, wie schon Theodor Mommsen (Neue Bruchstücke des Johannes von Antiochia und des Johannes Malalas, Hermes 6, 1872, 323-383, hier: 329 Anm. 1; auch in: ders., Gesammelte Schriften, Bd. 7, Berlin 1909, 710-750, hier: 715 Anm. 1) erkannte, aus derselben Quelle wie Joh. Ant. F 214 Müller = F 306 Roberto. Diese beiden Suda-Artikel gehen aber wohl nicht direkt auf Candidus zurück, sondern sind durch verlorene Teile des Johannes Antiochenus vermittelt: Roberto (s. Anm. 24), 712-713.

44 In der knappen Inhaltsangabe des Suda-Artikels $=\mathrm{T} 1$ wird nur die Regierungszeit Zenons erwähnt. Zudem hat Malchos vermutlich den Anschluß an Priskos gesucht, dessen Geschichtswerk wahrscheinlich bis zum Tode Leons führte. Ausführliche Erörterung der verschiedenen Möglichkeiten, die Angaben der Suda mit denen des Photios zu vereinen, bei Baldwin (s. Anm. 38), 96-98.

45 E. Gibbon, The Decline and Fall of the Roman Empire, ed. J. B. Bury, Bd. 4, London 1897, 170-175.

46 Der Begriff Kaiserkritik wurde von Berthold Rubin geprägt; ihm zufolge handelte es sich um den mit literarischen Topoi arbeitenden Ausdruck senatorischer Opposition gegen die Kaiserherrschaft: Das Zeitalter Justinians, Bd. 1, Berlin-West 1960, 234244; 473-484. F. Tinnefeld, Kategorien der Kaiserkritik in der byzantinischen Historiographie von Prokop bis Niketas Choniates, München 1971 hat demgegenüber mit Recht festgestellt, daß in Byzanz nur ganz vereinzelt Kritik an lebenden Kaisern geübt, sich ansonsten aber damit begnügt wurde, kritische Äußerungen byzantinischer Historiographen über Kaiser zusammenzustellen, ohne die zugrundeliegenden Kategorien zu analysieren. Die wahren Dimensionen des Themas hat erst Averil Cameron, Early Byzantine Kaiserkritik: Two Case Histories, BMGS 3, 1977, 1-17; auch in: dies., Continuity and Change in Early Byzantium, London 1981, Nr. IX am Beispiel der Quellen für Justin II. aufgezeigt.

47 Rubin (s. Anm. 46), 239 meinte: „Die wenigen Fragmente des Malchos (c. 480) ergeben nicht viel mehr als die Hochschätzung dieses Autors für den Senat." 
nicht vorhanden ${ }^{48}$ heute nicht mehr zutrifft, gibt es nach wie vor nur sehr wenige Beiträge, die sich speziell mit diesem Autor befassen. ${ }^{49}$

II.

Malchos muß in seinem Werk irgendwo erwähnt haben, daß er aus Philadelpheia in der Provinz Arabia stammte, aus Amman also, der Hauptstadt des heutigen Staates Jordanien. ${ }^{50}$ In den Fragmenten deutet wenig darauf hin, daß er sich dieser Region besonders verbunden fühlte und ihren Geschicken einen besonderen Platz in seinem Werk einräumte. Allenfalls könnte man erwägen, ob Malchos die Geschichte des arabischen Scheichs Imru' al-Qays, der 473 von Kaiser Leon zum Phylarchen der Araber in den Provinzen Palaestina Tertia und Arabia (kata Petraian) bestellt wurde, deswegen so ausführlich erzählt, ${ }^{51}$ weil er selbst in der Region verwurzelt war. Zwingend ist die Annahme indessen nicht: Die Aufmerksamkeit der Zeitgenossen wurde schon dadurch auf die arabische Grenze gelenkt, daß Anastasius dort Erfolge errungen hatte und sich dafür feiern ließ $;{ }^{52}$ die für den Indienhandel bedeutende Insel Iotabe, deren Besitz Imru' al-Qays durch Leon zugestanden worden war, befand sich seit 498 wieder in römischer Hand. ${ }^{53}$ Die heftige Kritik an Leons Entgegen-

48 Laqueur (s. Anm. 38), 857.

49 Baldwin (s. Anm. 38), 91-107; Blockley (s. Anm. 37), I, 71-85; 124-129; Cresci (s. Anm. 37), 21-62 (grundlegend); Blockley in Marasco (s. Anm. 19), 289-312. An der Oberfläche bleibt die neueste Darstellung bei Treadgold (s. Anm. 19), 103-107. Der Vorschlag von R. M. Errington, Malchos von Philadelpheia, Kaiser Zenon und die beiden Theoderiche, MH 40, 1983, 82-110, F 19 (=ELR 2) an der Stelle zu belassen, wo es überliefert ist (vor F $10=$ ELR 3), schafft mehr Probleme, als er löst: vgl. R. C. Blockley, On the Ordering of the Fragments of Malchus' History, Liverpool Classical Monthly 9, 1984, 152-153. Das Exzerpt ist wie das unmittelbar vorangehende (F $18=$ ELR 1) durch einen Überlieferungszufall an die falsche Stelle geraten und gehört ans Ende der Reihe in den „Excerpta de legationibus Romanorum“ (nach F $14=$ ELR 7).

50 Daß Malchos aus einer Stadt namens Philadelpheia stammte, ergibt sich aus Photios' Referat (Cod. $78=$ T 2, Z. 32) und der Überschrift der „Excerpta de legationibus

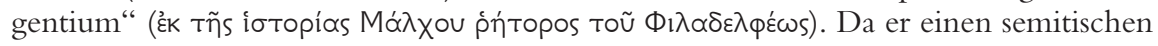
Namen trägt, kommen die lydische oder die isaurische Stadt dieses Namens kaum in Frage.

$51 \quad \mathrm{~F} 1=$ ELG 1.

52 Vgl. dazu Capizzi (s. Anm. 5), 174-179; I. Shahîd, Byzantium and the Arabs in the Fifth Century, Washington, DC 1989, 121-133; Haarer (s. Anm. 5), 29-47.

53 Theoph. AM 5990; vgl. Eustath. F 6 = Euagr. 3, 36. Die Insel, deren Bedeutung als Anlegeplatz für Indienfahrer und Zollstation auch durch Proc. BP 1, 19, 3-4; Chor. Or. 3, 67 bezeugt wird, ist nicht sicher lokalisiert. Gegen die Annahme, sie sei einem in Klysma stationierten commerciarius unterstellt gewesen (so nach Maurice Sartre im Kommentar zu IGLS XIII 9045 + 9046 Shahîd [s. Anm. 52], 132; Haarer [s. Anm. 5], 
kommen gegenüber dem arabischen Scheich beinhaltete daher ein Lob für den regierenden Kaiser. Im übrigen hatte Imru' al-Qays den Kaiser in Konstantinopel besucht und dabei großes Aufsehen erregt. ${ }^{54}$ Gerade hier dürfte man sich seiner daher noch lange erinnert haben.

Denn Malchos, der in der „Suda“ als Byzantier bezeichnet wird, schildert die Geschichte seiner Zeit aus der Perspektive des von Konstantin gegründeten neuen Rom, auch wenn er die Stadt in archaisierender Manier stets Byzanz nennt. Konstantinopel ist für Malchos die Stadt schlechthin; darum nennt er sie auch oftmals einfach „die Stadt““ ${ }^{55}$ Wenn Theoderich Strabo vor die Mauern Konstantinopels zieht, ist das für Malchos ein Angriff auf „die Stadt“, und wenn er wieder abzieht, wird dadurch „die Stadt“ von einer großen Gefahr befreit. Wäre er nämlich hineingelassen worden, so kommentiert Malchos, dann hätten die Isaurer „die Stadt“ in Brand gesteckt. ${ }^{56}$ Dem anderen Theoderich dagegen legt er den Wunsch in den Mund, in „die Stadt" aufgenommen zu werden, um dort nach römischer Art zu leben. ${ }^{57}$ Diese Fokalisierung kommt auch in der Verwendung eines Drinnen-DrauBen-Schema zum Ausdruck. So heißt es einmal, während Zenon auf Informationen „von draußen“ gewartet habe, habe man Leute ertappt, die Theoderich Strabo über die Vorgänge ,drinnen“ hätten informieren wollen. ${ }^{58}$

Der Eindruck, daß Malchos die Geschehnisse mit den Augen eines Bewohners der Hauptstadt sieht, wird durch die vielen Gesandtschaften verstärkt, die er in seinem Werk beschrieben hat. Denn mit wenigen Ausnahmen ist Konstantinopel ihr Ausgangs- oder Zielpunkt. Wir erkennen auch noch, daß Malchos innerstädtische Angelegenheiten ausführlich und mit genauer Kenntnis der Örtlichkeiten behandelt hat; er schilderte den großen Brand, der während der Usurpation des Basiliskos die Stoa Basilike mitsamt Bibliothek und den Palast des Lausus in Schutt und Asche legte. Malchos muß dabei sehr ins Detail gegangen sein, denn er erwähnte eine Homerausgabe und die

44-46), wendet sich mit einleuchtenden Gründen W. Brandes, Finanzverwaltung in Krisenzeiten. Untersuchungen zur byzantinischen Administration im 6.-9. Jahrhundert, Frankfurt/Main 2002, 255-263, bes. 261-263.

54 Zu Imru' al-Qays, der bei Malchos Amorkesos heißt, vgl. Shahîd (s. Anm. 52), 59 ff., bes. 106-113, der im übrigen darauf hinweist (61-63), daß der arabische Name, der sich hinter Amorkesos verbirgt, möglicherweise 'Amr ibn-Qays lautete.

55 F $19=$ ELR 2, Z. 4; Z. 25; ebenso F 6, Z. 6 (aus der Suda).

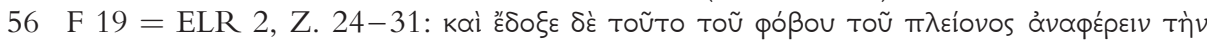

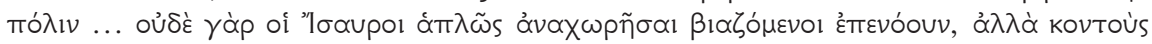

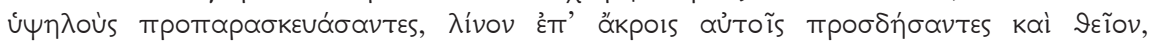

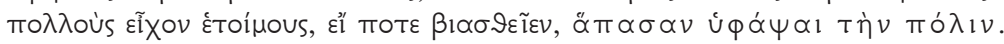

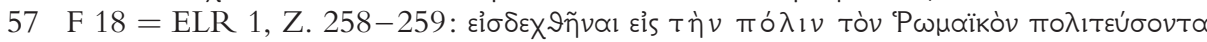
тро́тоv. In dem aus der Suda stammenden F 6 heißt es, der Prätoriumspräfekt Erythrius habe „der Stadt“ durch seinen Rücktritt Verdruß bereitet.

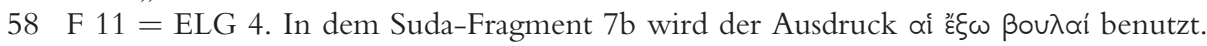


Statuensammlung im Palast des Lausus. ${ }^{59}$ Der Titel „Byzantinische Geschichte" (Byzantiaka), der nicht allein bei Photios, sondern auch in der Überschrift der konstantinischen Exzerpte belegt ist, war also durchaus programmatisch. ${ }^{60}$

Photios und der Suda-Artikel nennen Malchos übereinstimmend einen Sophisten. ${ }^{61}$ Er war also als Lehrer der Rhetorik tätig und zwar in Konstantinopel. In der Tat lassen die Fragmente noch erkennen, daß Malchos die Belange von Intellektuellen sehr wichtig nahm. So erwähnt er nicht bloß, daß Kaiser Leon den grammaticus Hyperechius verbannt hatte, sondern erzählt mit sichtlicher Entrüstung, daß dem Philosophen Eulogius ein Gehalt (siteresion) mit der Begründung verweigert wurde, man brauche das Geld für die Soldaten. ${ }^{62}$ Von dem Prätoriumspräfekten Laurentius weiß er zu berichten, er habe zuvor den ersten Rang unter den Anwälten innegehabt, die auf der großen Agora praktizierten. ${ }^{63}$ Ein standestypisches Interesse an Rang- und Besoldungsfragen ist auch in seinem ausführlichen Bericht über Pamprepius erkennbar, erfahren wir doch nicht bloß, wie dieser es geschafft hatte, in Konstantinopel eine besoldete Anstellung (syntaxis) als Dozent zu erlangen, sondern auch, daß das Gehalt teils vom Heermeister Illus und teils von der Staatskasse gezahlt wurde. ${ }^{64}$ Pamprepius, der sich später mit Illus gegen Zenon

59 F 7a $=$ Zon. 14, 2; daß Malchos den Brand im Jahre 476 sehr imposant und im Stile einer Tragödie dargestellt habe, vermerkt auch der Suda-Artikel $=$ T 1. Die Statuensammlung des Lausus wird bei Georgios Kedrenos (I, p. 564; 616 Bekker) eingehend beschrieben; nach C. Mango/M. Vickers/E. D. Francis, The Palace of Lausus at Constantinople and its Collection of Ancient Statues, Journal of the History of Collections 4, 1992, 89-98 geht diese Beschreibung letztlich ebenfalls auf Malchos zurück. Wenn F 2b = Suda s. v. 'Akókı Malchos zu Recht zugeschrieben würde, wäre gesichert, daß er auch auf kirchliche Bauten ausführlicher einging; dies ist jedoch eher unwahrscheinlich: vgl. dazu unten Anm. 68.

60 Die Überschrift der „Excerpta de legationibus Romanorum“ lautet: 'Ek Tñs ítopías

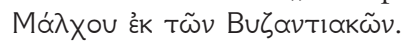

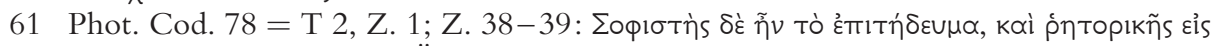

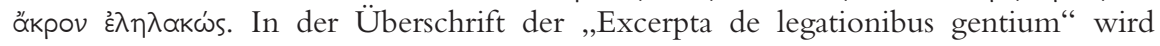

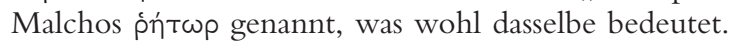

62 F 2a. Die Zuschreibung ist sicher, denn Malchos wird in diesem Suda-Artikel namentlich genannt. Für Hyperechius ist eine Reihe Schriften grammatischen Inhalts bezeugt: PLRE II Hyperechius; Kaster (s. Anm. 10), 297 Nr. 97. Der Philosoph wird nur an der vorliegenden Stelle erwähnt.

63 F 7b, Z. 10-12 (aus der Suda). Laurentius ist nur an dieser Stelle erwähnt.

64 F 20, Z. 13-16. Weil ein Stück aus diesem anonymen Suda-Artikel an anderer Stelle unter dem Namen des Malchos zitiert wird, ist die Zuschreibung an Malchos gesichert. Pamprepius' Erfolg erregte unter Intellektuellen großes Aufsehen; nach Damasc. V.Isid. F 178 trug er mit einem Vortrag über die Seele den Sieg über andere Redner davon, die auf Wunsch des Illus dasselbe Thema behandelt hatten. 
erhoben hatte und mit diesem untergegangen war, ${ }^{65}$ wird von Malchos mit sichtlicher Sympathie geschildert; er wird als ein guter und rechtschaffener Mann bezeichnet, der nur deswegen in der Ruf geraten sei, Magie zu praktizieren, weil er seine heidnische Gesinnung vor der christlichen Bevölkerung Konstantinopels freimütig bekannt habe. ${ }^{66} \mathrm{Im}$ selben Zusammenhang legt Malchos dem neuplatonischen Philosophen Proklos das schmückende Beiwort „der Große“ bei. Ob man daraus schließen kann, daß Malchos selbst Heide war, ${ }^{67}$ ist unsicher - Photios, der das Werk viel besser kannte als wir, war jedenfalls nicht dieser Meinung. ${ }^{68}$ In jedem Fall zeigt die Behandlung von Pamprepius und Proklos, daß Malchos sein Urteil über Personen nicht von deren religiösem Bekenntnis abhängig machte. Der Kontrast zu Candidus, der den Heiden Pamprepius für den Untergang des orthodoxen Christen Illus verantwortlich machte, könnte kaum größer sein.

Auf die unteren Schichten der hauptstädtischen Bevölkerung, das „Gesindel“", wie er es einmal nennt, ${ }^{69}$ sieht Malchos von oben herab, was ihn freilich nicht hindert, Mitgefühl für arme Handwerker zu äußern, denen übel mitgespielt wird. ${ }^{70}$ Das christliche Volk von Konstantinopel randaliert gerne ${ }^{71}$

65 Quellen, Literatur und umsichtige Diskussion bei Kaster (s. Anm. 10), 329-332 Nr. 114.

66 F 20, Z. 9-13.

67 So Laqueur (s. Anm. 38), 856. Blockley (s. Anm. 37), I, 77 und Cresci (s. Anm. 37), 22-24 halten ihn dagegen für einen Christen. Baldwin (s. Anm. 38), 94-96 legt sich nicht fest.

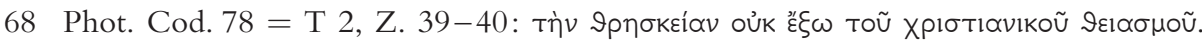
Die Stellen, an denen Malchos auf christliche Angelegenheiten eingeht, geben für die Frage wenig aus, da die sprachliche Distanzierung von christlichen Termini ein Er-

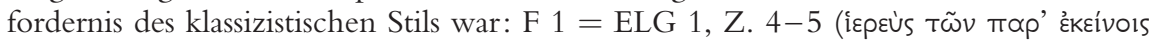

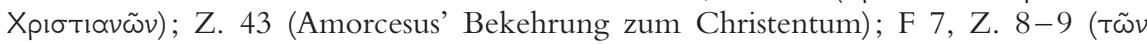

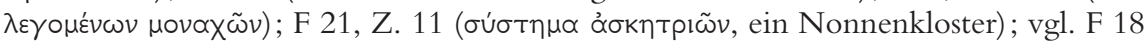

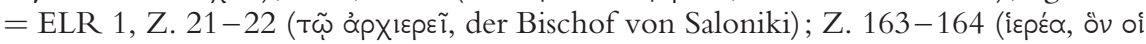

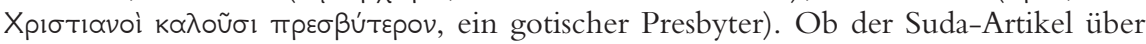
Bischof Acacius von Konstantinopel tatsächlich aus Malchos geschöpft ist, wie Cresci annimmt (F 2b), ist zweifelhaft; Blockley führt ihn unter den Anonyma auf, Baldwin (s. Anm. 38), 100-101 weist ihn Candidus zu, zu dem er tatsächlich besser zu passen scheint.

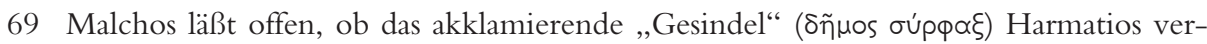
spotten oder ihm schmeicheln will: F 8, Z. 19-22. F 8 setzt sich aus mehreren SudaArtikeln zusammen; Baldwin (s. Anm. 38), 100 begründet ihre Zuschreibung an Malchos durch den Hinweis auf mehrere hapax legomena und das Interesse für erotische Passionen. Für Malchos als Quelle des Suda-Artikels über Harmatios spricht zudem die Tatsache, daß F 11 = ELG 4, Z. 20-22 einen klaren Rückverweis auf F 8, Z. 28-29 enthält.

70 F 7, Z. 9-11. Auch bei diesem Suda-Artikel sprechen Form und Inhalt für Malchos.

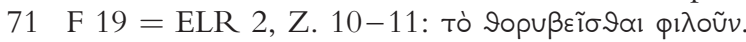


und ist unfähig, die kaiserliche Propaganda zu durchschauen. ${ }^{72}$ Es ist mit dem Vorwurf der Magie schnell bei der Hand, wenn einer freimütig bekennt, kein Christ zu sein und aufgrund seines politischen Urteilsvermögens Entwicklungen vorhersagt, mit denen es selbst nicht gerechnet hat. ${ }^{73}$ Dem Senat als Institution bringt Malchos dagegen großen Respekt entgegen; daß ein Barbar wie Imru' al-Qays mit einem Ehrensitz im Senat und dem Titel protopatricius ausgezeichnet wird, ist für ihn der größte Schimpf, den man den Römern antun kann. ${ }^{74}$ Patrizischer Rang wird auch sonst wiederholt vermerkt und ausdrücklich als Auszeichnung für diejenigen bezeichnet, die sich bei den Römern die größten Verdienste erworben hätten. ${ }^{75}$ Auch einzelne Senatoren wie der ehemalige Stadtpräfekt Adamantius ${ }^{76}$ werden mit großem Interesse und merklicher Sympathie geschildert; für Severus, der als Gesandter Zenons zu Geiserich ging, stimmt Malchos sogar eine regelrechte Lobeshymne an. ${ }^{77}$

Als wohlhabender und gebildeter Zivilist fühlt sich Malchos vor allem von zwei Seiten bedroht: einerseits durch den Fiskus und durch Sykophanten, die mit ihm kooperieren, und andererseits durch das barbarisierte Militär, das er mit Mißtrauen und Argwohn betrachtet. Das Motiv des Steuerdrucks begegnet mehrfach: Leon habe die Untertanen ausgeplündert, ${ }^{78}$ Zenon die Steuerschraube angezogen, sobald er das von seinem Vorgänger angehäufte Vermögen verschleudert hatte, ${ }^{79}$ Basiliskos sich auf Kosten der Städte maßlos bereichert, bis diese nicht mehr zahlen konnten. ${ }^{80}$ Diese Klagen sind nicht bloß deswegen wenig überraschend, weil die Steuerpolitik in der spätrömi-

72 F 2a, Z.1-5. Malchos wird in diesem Suda-Fragment namentlich zitiert: Die Menge glaubt, Leon habe von allen Vorgängern am meisten Fortune gehabt und bei Untertanen und Barbaren den größten Respekt genossen.

73 F 20, Z. 9-13. Als Pamprepius das Scheitern der Usurpation Marcians vorhersagt, meint die Menge, er sei - aufgrund magischer Fähigkeiten - für alles verantwortlich, was anders ausgeht, als es ihrer Erwartung entspricht, „wie die Menge zu tun pflegt“"

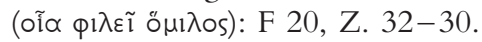

74 F $1=$ ELG 1, Z. 40-42.

75 F $3=$ ELR 3, Z. $5-7$ (Severus); F $10=$ ELG 3, Z. $9+31$ (Odovakar); F $18=$ ELR 1,

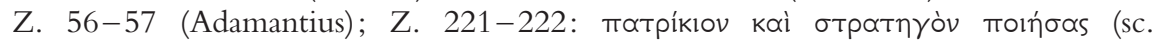

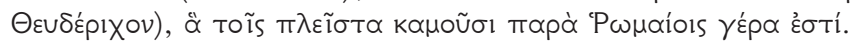

76 Malchos führt Adamantius ein, indem er seinen Vater, den Prätoriumspräfekten und Konsul Vivianus (PLRE II Vivianus 2), seinen Rang und das höchste Amt, die Stadtpräfektur, nennt: F $18=$ ELR 1, Z. 55-57; in diesem Amt ist er auch durch drei an ihn adressierte Gesetze belegt: PLRE II Adamantius 2. Seine Mission wird so detailliert beschrieben, daß man vermuten kann, Malchos habe ihn persönlich gekannt.

77 F 3 = ELR 3. Malchos rühmt seine Mäßigung ( $\sigma \omega \phi p \circ \sigma u ́ v \eta)$ und Gerechtigkeit

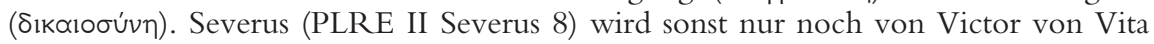
(Hist. Pers. 1, 51) erwähnt.

78 F 2a.

79 F 6. Das Fragment, das aus der Suda stammt, wird allgemein Malchos zugeschrieben.

80 F 7; F 7b. 
schen Historiographie bei der Beurteilung von Kaisern auch sonst eine erhebliche Rolle spielt. ${ }^{81}$ Sie passen auch gut in die frühen Jahre des Anastasius, der durch die Abschaffung der collatio lustralis (498) Popularität gewann. ${ }^{82}$ Als verdeckte Kritik wäre sie wohl nur dann zu lesen, wenn Malchos in der Zeit nach dem Perserkrieg des Anastasius (502-506) schrieb, als der Kaiser im Ruf stand, auf Kosten der Untertanen zu sparen. ${ }^{83}$ Malchos' finanzpolitische Analysen sind jedenfalls simpel: Sein Vorbild ist der Prätoriumspräfekt Erythrius, der lieber von seinem Amt zurücktritt, als den Untertanen höhere Steuern aufzubürden oder Steuerschuldner an den Bettelstab zu bringen, obwohl die Staatskasse leer ist. Daß diese mißliche Situation eintreten konnte, führt Malchos darauf zurück, daß Zenon gegenüber seinen Freunden zu freigiebig war und ihnen zugleich zu wenig auf die Finger schaute. ${ }^{84}$

81 Das Phänomen ist nicht unbemerkt geblieben - vgl. etwa Rubin (s. Anm. 46), 239; Z. V. Udal'cova, Le monde vu par les historiens byzantins du IVe au VIIe siècles, BSI 33, 1972, 193-213, hier: 196; Cameron (s. Anm. 46), 16-17, aber bislang nicht näher untersucht; Tinnefeld (s. Anm. 46) hat ihm keine Beachtung geschenkt. Ich kann hier nur einige zufällig aufgelesene Beispiele bringen: Amm. 30, 9, 1 (Valentinian I.); 31, 14, 2 (Valens); Prisc. F 5 Müller (vgl. F 8 Müller, 47, Z. 15-50, Z. 20 in der Ausgabe von F. Bornmann, Prisci Panitae fragmenta, Florenz 1979); Zos. 2, 38 (Konstantin I.); 4, 28-29 (Theodosius I.); Proc. An. 19-24 (Justinian I.); Agath. 5, 14 (Justinian I.); Joh. Eph. H. E. 3, 11; 14 (Tiberius II.); 5, 20 (Maurikios); Euagr. 3, 39-42 (Anastasius); 4, 30 (Justinian I.); 5, 13 (Tiberius II.).

82 Capizzi (s. Anm. 5), 143-146; Haarer (s. Anm. 5), 194-197 (mit allen Quellen). Die positive Resonanz bei den Untertanen belegen besonders eindrücklich Priscian. Pan. 149-161; Proc. Pan. 13; Jos. Styl. 31.

83 Neben den Spottepigrammen aus Konstantinopel (Joh. Lyd. De mag. 3, $46=$ Anth. Pal. 11, $270+$ 271), Malal. 16, 20, p. 408 und Joh. Ant. F 215 Müller $=312$ Roberto ist hier auch das „Orakel von Baalbek“ zu erwähnen, das für die Zeit nach Zenon einen Kaiser prophezeit, der alle Bettler haßt und viele Leute aus dem Volk zugrunde richtet: P. J. Alexander, The Oracle of Baalbek. The Tiburtine Sibyl in Greek Dress, Washington, DC 1967, V. 168-169. Zenon dagegen erscheint in diesem apokalyptischen Text aus der Regierungszeit des Anastasius als ein Herrscher, der sein Kaisertum zwar nicht von Gott erhalten hat, aber beim gesamten Volk Gefallen finde, weil er die Armen liebe und die Mächtigen und Reichen demütige: V. 155-161.

84 F 6 (aus der Suda). Der Ägypter Erythrius hatte schon unter Leon zweimal die Prätoriumspräfektur bekleidet, bevor er das Amt unter Zenon ein drittes Mal übernahm: PLRE II Erythrius 1. Er war in Konstantinopel nicht unumstritten; nach Damasc. V.Isid. F 173 bekämpften er und der Philosoph Ammonius (PLRE II Ammonius 6) sich bis aufs Messer und brachten sich dadurch gegenseitig in höchste Gefahr. Zudem scheint ein gewisser Panolbius, den wir nur aus der Suda (s. v. $\alpha v o ́ \lambda \beta ı$ ı) kennen, Verse gegen (трòs) Erythrius (und einige andere) verfaßt zu haben. Ob man daraus schließen kann, Malchos' Enkomion auf Erythrius sei „,part of some literary and political infighting“" (so Baldwin [s. Anm. 38], 104 nach Alan Cameron, Wandering Poets: A Literary Movement in Byzantine Egypt, Historia 14, 1965, 470-509, hier: 506-507), scheint indessen fraglich. 
Freilich sind Verschwendung durch den Kaiser und Unterschleif der Beamten nicht die einzigen Gründe, weshalb der Staat unter Leon und Zenon permanent in Geldnot ist. Malchos betont wiederholt, daß das Militär eine schwere, kaum zu tragende Belastung für den Staat darstelle. Kaiser Leon legt er den Ausspruch in den Mund: „Möge es doch zu meiner Zeit geschehen, daß die Lehrer bekommen, was die Soldaten erhalten! ${ }^{\mid 65}$ Dieser Wunsch gilt für alle Truppenteile, vor allem aber für die föderierten Gotenheere. ${ }^{86}$ Malchos ist überzeugt, daß ihre Forderungen jedes Maß überschritten. Diese Auffassung auszusprechen, überläßt er dem Senat: Eigentlich kosteten schon die regulären Truppen mehr Geld, als man zur Verfügung habe. Erst recht sei es unmöglich, zusätzlich noch zwei Föderatenheere zu unterhalten. Mehr als ein Föderatenheer sei unter keinen Umständen finanzierbar. ${ }^{87}$ Diese Analyse wird durch die Darstellung untermauert, denn Malchos beziffert mehrfach die hohen Summen, die für die Dienste gotischer Föderaten zu entrichten waren. ${ }^{88}$

Soldaten sind nach Auffassung des Malchos aber nicht nur teuer, sondern auch gefährlich; mit Ausschreitungen und Krawallen ist stets zu rechnen: So erzählt er, wie ein gotischer Föderat in Arkadioupolis den Heermeister Heraclius anrempelte und ihm, als er dafür zur Rede gestellt wurde, kurzerhand den Kopf abschlug. Malchos hat sich hier für eine Version entschieden, in der die unkontrollierbare Gewalttätigkeit der Goten akzentuiert wird; Candidus führte den Tod des Heraclius nämlich auf einen Anschlag des Gotenführers Theoderich Strabo zurück. ${ }^{89}$ An einer anderen Stelle erzählt Malchos, wie der illyrische Prätoriumspräfekt Johannes in Thessaloniki mit knapper Not Soldaten entkommt, die mit Schwertern auf ihn losgehen. ${ }^{90}$

85 F 2a, Z. 15-20.

86 Mehrfach wird angesprochen, daß Ausrüstung und Verpflegung für marschierende Truppen von den Städten gestellt werden: Als Zenon sich entschließt, gegen Theoderich Strabo ins Feld zu ziehen, werden ,Lastwagen gebaut, Rinder gekauft, Getreide und alles, was ein Heer sonst noch braucht, bereitgestellt": F 14 = ELR 7, Z. 22-24; der Heermeister Sebastianus erläßt „,den Städten“ den Bau von Wagen für das Heer, nachdem er den Troß Theoderichs erbeutet hat: F 18 = ELR 1, Z. 297-301.

87 F 2a, Z. 14-19; F $11=$ ELG 4, Z. 14-15; Heeresbedarf: Wagen, Rinder, Getreide $($ F $14=$ ELR 7, Z. 22-25), Wagen (F $18=$ ELR 1, Z. 297-301).

88 Jahresgelder für Strabo (F 2 = ELG 2, Z. 25-27): 2000 Pfund Gold; Siegespreis für Theoderich (F 16 = ELG 6, Z. 29-31): 1000 Pfund Gold, 10.000 Pfund Silber, dazu eine jährliche Rente von 10.000 Goldstücken.

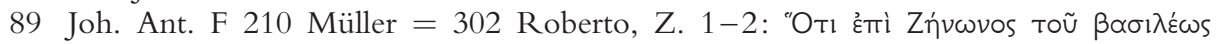

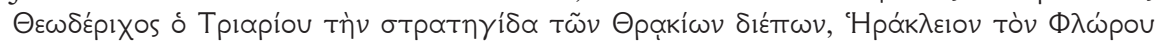

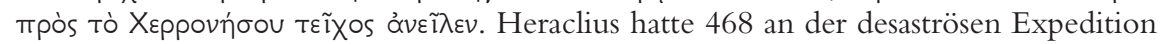
gegen die Vandalen teilgenommen (PLRE II Heraclius 4); Malchos hielt ihn für einen Draufgänger, dem es an Besonnenheit fehlte: F 5 (aus der Suda).

90 F $18=$ ELR 1, Z. 70-73; vgl. Z. 6-23. 
Von den regulären Truppen des Kaisers hält der Zivilist Malchos wenig. Der Eindruck, es handle sich um einen nichtsnutzigen und feigen Haufen, prägt sich dem Leser um so nachhaltiger ein, als Malchos die Soldaten sich selbst der Feigheit und Verweichlichung bezichtigen läßt. ${ }^{91}$ Tatsächlich wird diese Selbstanklage durch die Erzählung an mehreren Stellen implizit oder explizit bestätigt: Soldaten schmieren ihre Offiziere, um nicht selbst in den Krieg ziehen zu müssen. ${ }^{92}$ Zenon muß verhandeln, weil er sieht, daß niemand gegen Theoderich kämpfen will. ${ }^{93}$ Die Garnison von Epidamnos gibt die Stadt kampflos preis, als sich das Gerücht verbreitet, es nahe ein gotisches Heer, obwohl sie ihm nach dem Urteil des Malchos sehr wohl gewachsen gewesen wäre. ${ }^{94}$ Die Besatzung eines Kastells läuft bei Anblick gotischer Angreifer einfach davon, statt zu kämpfen oder zumindest die Tore zu schließen, wie Malchos tadelnd anmerkt. ${ }^{95}$

Das Kaiserideal des Malchos ergibt sich e contrario aus dem, was er an Leon, Basiliskos und Zenon bemängelt: Zunächst einmal erhebt ein guter Kaiser möglichst wenig Steuern. Weiterhin verleiht er denen, die es verdient haben, Ehren und Würden, ${ }^{96}$ läßt andere an seinem Reichtum teilhaben und enthält sich ungerechtfertigter Anklagen gegen seine Untertanen. Der gute Kaiser sucht sich seine Freunde und Berater sorgfältig aus und pflegt einen maßvollen und sparsamen Lebenswandel. Er darf ruhig einmal zornig werden, aber seinem Zorn nicht freien Lauf lassen oder nachtragend sein. ${ }^{97}$ Neben der Mäßigung sind auch Ehrliebe, Mitgefühl und Milde Eigenschaften, die einem guten Kaiser in den Augen des Malchos wohl anstehen. ${ }^{98}$ Er ist sich der Würde seines Amtes bewußt und achtet darauf, daß er allseits gefürchtet wird, insbesondere natürlich von den Barbaren. ${ }^{99}$ Er soll tapfer, aber nicht unbesonnen sein und vor allem selbst das Kommando über die Truppen führen. ${ }^{100}$ Von der persönlichen Anwesenheit des Kaisers bei den Truppen erwartet sich Malchos wahre Wunderdinge: Als Zenon den Soldaten einmal ankündigt, er werde selbst an der Spitze seiner Truppen ins Feld ziehen, steigt ihre Kampfmoral sogleich ins Unermeßliche, um ebenso schnell wieder auf den Nullpunkt zu

91 F $16=$ ELG 6, Z. 50-56.

92 F $16=$ ELG 6, Z. 40-44.

93 F $18=\operatorname{ELR} 1$, Z. 25.

94 F $18=$ ELR 1, Z. $98-101$.

95 F $18=$ ELR 1, Z. 125-131

96 F $1=$ ELG 1 (Amorcesus); F $3=$ ELR 3 (Severus); F 7b (Erythrius).

97 F 9, Z. 11-14.

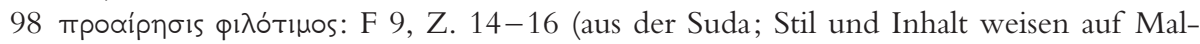

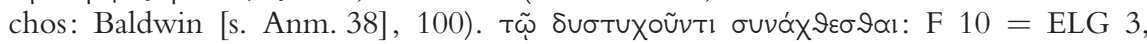
Z. 32-34. Milde: F $11=E L G ~ 4$, Z. 44-45.

99 F $1=$ ELG 1; F 2a, Z. 1-5.

100 Tapferkeit: F 5 (der Heermeister Heraclius); F 7 (Basiliskos); vgl. F $10=$ ELG 3 (Lob des römischen Senats für Odovakar). 
sinken, als der Kaiser, von seiner angeborenen Feigheit überwältigt, sich wieder zurückzieht. ${ }^{101}$ Da Malchos hier eine Erwartung zum Ausdruck bringt, der kein römischer Kaiser der letzten 100 Jahre genügt hatte, ist es durchaus fraglich, ob seine Darstellung in diesem Punkt als indirekte Kritik an Anastasius $\mathrm{zu}$ lesen ist.

Gemessen an diesen Kriterien, erwiesen sich die Kaiser Leon und Zenon als Versager. Über Leon fällte Malchos ein vernichtendes Urteil. Leon ist für Malchos eine „Herberge jeder Art von Schlechtigkeit“, vor allem aber grausam und habgierig. Er scheut sich darum nicht, Leon den Spitznamen ,der Schlächter" beizulegen, den er für den Mord an Aspar und Ardabur erhalten hatte. ${ }^{102}$ Leon sei maßlos in seinem Zorn gewesen ${ }^{103}$ und habe keine Skrupel gekannt, die Untertanen durch falsche Anklagen um ihr Vermögen zu bringen. ${ }^{104}$ Den Ruf, Fortune zu haben und allen Untertanen, einschließlich der Barbaren, Furcht einzuflößen, habe er zu Unrecht genossen. ${ }^{105}$ In Wahrheit war Leon nach Malchos dumm und besaß keinen Sinn für die Würde seines Amtes; weil es ihm an Klugheit und Ehrgefühl fehlte, so führt Malchos aus, habe er einem Barbaren wie Imru' al-Qays Einblick in die mangelnde Verteidigungsbereitschaft der Provinzstädte gewährt, indem er ihn nach Konstantinopel kommen ließ, und aus demselben Grund habe er ihm jede Achtung vor Kaiser und Senat genommen, indem er ihn an der kaiserlichen Tafel speisen und auf einem Ehrenplatz an Senatssitzungen teilnehmen ließ. ${ }^{106} \mathrm{Da}$ Leon eines qualvollen Todes starb, hat Malchos genüßlich ausgemalt, ${ }^{107}$ weil er darin die gerechte Strafe für dessen Sünden sah. ${ }^{108}$

Malchos' Urteil über Zenon fiel differenzierter aus. Er sei weniger grausam gewesen und auch nicht so unerbittlich in seinem Zorn. Bei Malchos wurde nicht Zenon als Intrigant gezeichnet wie bei Eustathios, sondern dessen Schwiegermutter Verina, die erst gegen Zenon und dann gegen Illus ein Komplott geschmiedet habe. ${ }^{109}$ Malchos billigte Zenon denn auch zu, daß er

101 F $16=$ ELG 6, Z. 39-65.

102 F $1=$ ELG 1, Z. 2.

103 F 9, Z. 11-14. Vom Zorn Leons ist auch im Suda-Artikel über Bischof Acacius die Rede, der Malchos wohl zu Unrecht zugeschrieben wird (vgl. oben Anm. 68): F 2b, Z. 8-15.

104 F 2a, Z. 5-11; F 9, Z. 18-19.

105 F 2a, Z. $1-5$.

106 F $1=$ ELG 1, Z. 29-53.

107 F 2d; Phot. Cod. $78=$ T 2, Z. 3-4.

108 Tod als göttliche Vergeltung für Vergehen: F 9, Z. 46-49 (der Thronfolger Zenon); vgl. F $4=$ ELR 4, Z. 17-20.

109 Phot. Cod. $78=$ T 2, Z. 15-21. Verinas Einfluß wird auch in den Fragmenten an mehreren Stellen deutlich: F $10=$ ELG 3, Z. 35-36 (Verina setzt sich für Iulius Nepos ein); F $17=$ ELR 9, Z. 12-13 (Theoderich Strabo ist betrübt, daß weder Zenon noch Verina etwas gegen die Plünderungszüge seines Rivalen unternehmen); F $18=$ ELR 1, 
in vielen Dingen ehrliebend gewesen sei, wenngleich er einschränkend hinzufügt, es sei ihm mehr um die Wirkung auf andere gegangen. ${ }^{110}$ Zenon war für Malchos auch nicht so versessen auf Einnahmen und Gewinn wie Leon und fingierte daher keine oder jedenfalls fast keine Anklagen gegen die Besitzenden. ${ }^{111}$ Allerdings konstatierte Malchos bei Zenon auch erhebliche Defizite: Vor allem sei er unkriegerisch gewesen ${ }^{112}$ und habe von den Regierungsgeschäften keine Ahnung gehabt. ${ }^{113} \mathrm{Daß}$ Zenon nicht bloß den Usurpator Basiliskos, sondern auch dessen Frau und Sohn umbringen ließ, hat Malchos wohl deswegen mißbilligt, weil es seiner Vorstellung von Milde widersprach. ${ }^{114}$ Dennoch, so erklärt Malchos, hätten die Römer sich unter Zenon eines guten Kaisertums erfreut, wenn er nicht von seiner Umgebung völlig abhängig gewesen wäre. ${ }^{115}$ Malchos hat also Zenon als Person keineswegs rundheraus verdammt. Zenon war für ihn ein Kaiser mit guten Anlagen, nur eben zu schwach, um sich gegen seine Umgebung durchzusetzen. Eben deshalb ist er für das, was unter seiner Herrschaft und in seinem Namen geschah, auch nur bedingt verantwortlich.

Malchos griff hier auf ein altbewährtes Deutungsmuster zurück, das es ihm erlaubte, die Regierung Zenons kritisch darzustellen, ohne die Legitimität eines Kaisers in Frage zu stellen, dessen Gemahlin nach wie vor Kaiserin war. Dieses Deutungsmuster entsprach den Vorgaben des kaiserlichen Hofes, wie es sich in der Panegyrik spiegelt. Verina war tot, und auch Zenons Vertrauensleute waren bequeme Sündenböcke, seit sie ihre Macht eingebüßt hatten. ${ }^{116}$

Z. 80-81 (der Gote Sidimund ein Vertrauter der Verina); F 20, Z. $20-21$ (тทे

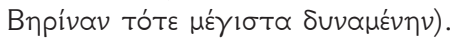

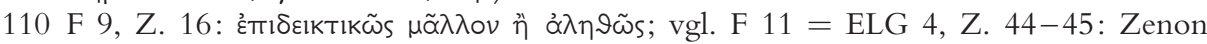
möchte den Eindruck vermeiden, er wolle Todesurteile und Hinrichtungen.

111 F 9, Z. 18-21.

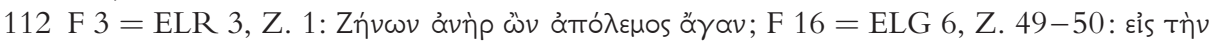

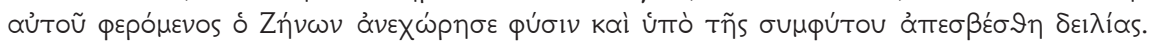

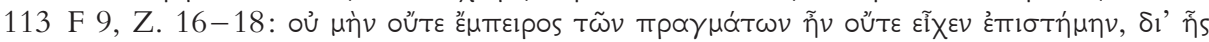

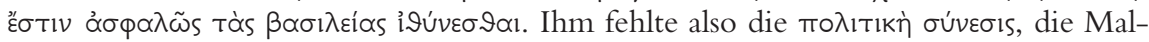
chos direkt Pamprepius (F 20, Z. 25-26) und indirekt, durch den Mund des weströmischen Senats, auch Odovakar (F $10=$ ELG 3, Z. 8-9) zuschreibt.

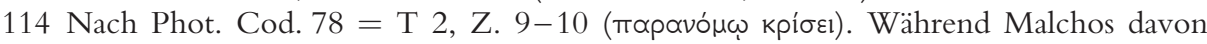
sprach, daß Basiliskos durch das Schwert hingerichtet worden sei, schilderte Candidus (Phot. Cod. 79, Z. 73-75), wie er durch einen Trick des Harmatios mit Frau und Kindern aus dem Kirchenasyl gelockt und nach Kappadokien verbannt worden sei, wo man sie zusammen umgebracht habe. Zur Familie des Basiliskos vgl. W. Brandes, Familienbande? Odoaker, Basiliskos und Harmatios, Klio 75, 1993, 407-436, bes. $432-436$.

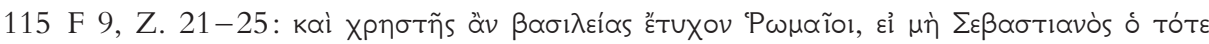

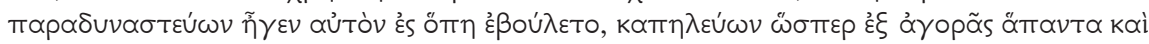

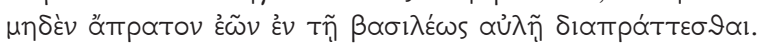

116 Auch die scharfe Kritik an Epinicus (PLRE II Epinicus), der unter Basiliskos Präfekt gewesen war, seine Laufbahn aber unter Zenon zunächst fortgesetzt hatte (F 7b), barg 
Malchos konnte unbesorgt behaupten, es seien kaiserliche Beamte gewesen, die den Staatsschatz vergeudet ${ }^{117}$ und den präsumptiven Thronfolger Zenon verdorben hätten. ${ }^{118}$ Wenn Ämter unter Zenon zu überhöhten Preisen und ohne Rücksicht auf persönliche Eignung verkauft wurden, so lag das an dessen Prätoriumspräfekten Sebastianus. ${ }^{119}$ Am härtesten geht Malchos mit Longinus, dem von Anastasius verbannten Bruder Zenons, ins Gericht: Longinus erscheint als Wüstling und Verschwender, der auf fremden Besitz Hypotheken aufnimmt und Verbrechern für Geld seine Unterstützung leiht; er beschäftigt zahllose Kuppler und schreckt nicht einmal davor zurück, Asketinnen mit sanfter Gewalt zum Bruch ihres Keuschheitsgelübdes zu bewegen. ${ }^{120}$

Leider bieten die erhaltenen Reste nur wenige Anhaltspunkte zur Beantwortung der Frage, ob Malchos wie Eustathios, Josua Stylites und Zacharias der Auffassung war, daß die Regierung Zenons mit der Vorherrschaft „der“ Isaurer am Hof und damit im Reich identisch gewesen sei. Nicht jeder, der damals Macht oder Einfluß besaß, war für Malchos ein Schurke; Senatoren wie Severus und Adamantius, die sich Zenon zur Verfügung gestellt hatten, werden von ihm durchaus positiv gezeichnet. Wir können jedoch sicher sein, daß Malchos die Vertreibung der Isaurer aus Konstantinopel begrüßt hat, denn er stellt ausdrücklich fest, daß die Isaurer nicht gezögert hätten, die Stadt in Brand zu stecken, wenn es Theoderich Strabo gelungen wäre, hinein zu gelangen, bevor der Usurpator Marcian niedergeschlagen wurde. ${ }^{121}$ Dieser Plan war für Malchos unverzeihlich.

III.

Gesellschaftsbild und Kaiserideal des Malchos können und müssen zu einem erheblichen Teil aus Fragmenten erschlossen werden, die ohne Zusammenhang überliefert sind und im Wortlaut stark vom Original abweichen können. Einen deutlichen Eindruck davon, wie Malchos geschichtliches Handeln darstellte, vermitteln jedoch allein die wörtlichen Fragmente aus den Kon-

für Malchos kein unkalkulierbares Risiko, da Epinicus 480 als Verschwörer hingerichtet worden war: Joh. Ant. F 211 Müller = F 303 Roberto, Z. 70-73.

117 F 6, Z. 11-15; F 9, Z. 37-38. Auch Basiliskos ließ sich von Betrügern leicht hereinlegen: $F 7$.

118 F 9, Z. 34-49.

119 F 9, Z. 25-33. Sebastianus ist durch zahlreiche an ihn adressierte Gesetze von 476480 und dann noch einmal 484 als Prätoriumspräfekt belegt: PLRE II Sebastianus 5. Nach F 12 = ELR 6 stieg der Preis, der für eine ägyptische Statthalterschaft zu entrichten war, unter Zenon von 50 auf 500 Pfund Gold.

120 F 21.

121 F $19=$ ELR 2, Z. 24-31; zitiert oben Anm. 56. In F $16=$ ELG 6, Z. $17-19$ verlangt Strabo von Zenon, daß Illus und andere Isaurer, denen er vertraue, einen Eid leisten sollten, um des Kaisers Worte zu bekräftigen. 
stantinischen Exzerpten, die von den Beziehungen der Kaiser Leon und Zenon zu auswärtigen Mächten, vor allem den beiden Gotenführern namens Theoderich, handeln. ${ }^{122}$ Malchos präsentiert sich hier als Erzähler, der die Tradition der klassischen griechischen Historiographie fortsetzt. Sein klarer Stil, der Photios entzückte, ist an Herodot, Thukydides und Xenophon geschult, deren Werken er viele Ausdrücke und Wendungen verdankt, wenngleich er technische Begriffe nicht um jeden Preis vermeidet und auch viele Worte selbst neu gebildet hat. ${ }^{123}$

Wenn vor allem die Suda-Fragmente belegen, daß Malchos zur personalisierenden Deutung und moralisierenden Bewertung kaiserlichen Handelns neigte, so lehren die Fragmente aus den Konstantinischen Exzerpten, daß er alle Darstellungsmittel zu handhaben wußte, die die klassische Historiographie zur Verlebendigung und Verdeutlichung des Geschehens entwickelt hatte. Sie bestätigen den Eindruck, daß Malchos sich wie viele spätrömische Geschichtsschreiber nicht mit der Rolle eines Erzählers zufriedengab, der hinter seinem Werk zurücktritt, sondern seine Meinung mitunter ganz unverblümt aussprach - etwa im Bericht über Imru' al-Qais. ${ }^{124}$ Er fand immer wieder Gelegenheit, Luxus (Tryphe) und Verweichlichung (Malakia) anzuprangern, und zwar nicht nur bei den Römern: Den Vandalen stellte er die Diagnose, sie vernachlässigten die militärischen Rüstungen, weil sie nach dem Tode des Geiserich völlig verweichlicht seien. ${ }^{125}$ Malchos nutzte das dramatische Potential seines Stoffs, um seine Leser zu rühren und zu erschüttern, indem er pathetische Beschreibungen von Katastrophen einlegte und Peripetien und die Unbeständigkeit des Schicksals im Leben der Protagonisten effektvoll ausge-

122 Photios (Cod. $78=$ T 2, Z. 22-26) bezeugt, daß westliche Angelegenheiten im Werk des Malchos ausführlich behandelt wurden. Tatsächlich haben sich in den „Excerpta“ drei Fragmente erhalten, die von den Beziehungen Leons und Zenons zum Westen handeln: F 3 = ELR 3 (Gesandtschaft Leons an Geiserich); F $10=$ ELG 3 (Gesandtschaften Odovakars und Iulius' Nepos an Zenon); F 13 = ELG 5 (Gesandtschaft Hunerichs an Zenon). Die Beziehungen zum Perserreich werden in den Fragmenten nur einmal und auch dort nur indirekt berührt: F 1 = ELG 1 (Amorcesus in Konstantinopel).

123 Phot. Cod. 78 = T 2, Z. 32-37; Baldwin (s. Anm. 38), 105-107; Cresci (s. Anm. 37), $41-48$.

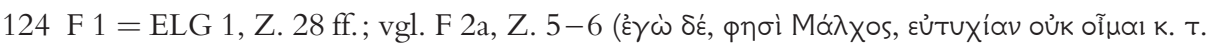
ג.); F $18=$ ELR 1, Z. 201-202; 225. Laqueur (s. Anm. 38), 856 schreibt Malchos hingegen den schriftstellerischen Grundsatz zu, auf eine moralische Bewertung des Geschehens zu verzichten: „Er stellt die Ereignisse in ihrem äußeren Verlaufe dar und verliert dabei kein Wort der Kritik." Diese Deutung beruht auf einer selektiven Lektüre der Fragmente.

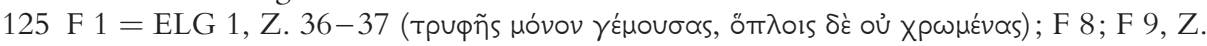
34-49; F $13=$ ELG 5, Z. 18-23 (Vandalen); F 21. 
staltete. ${ }^{126}$ Vor allem enthielt das Werk sehr viele Reden, direkte und indirekte, die wesentlich dazu beitragen, daß die Erzählung einen ausgesprochen multiperspektivischen Charakter trägt. In den Exzerpten, die sich auf die Auseinandersetzungen zwischen Zenon, Strabo und Theoderich beziehen, treten sie besonders gehäuft auf.

Da diese Exzerpte nicht bloß teilweise sehr ausführlich, sondern häufig auch eng aufeinander bezogen sind, lassen sie Malchos' Erzähltechnik recht deutlich erkennen; sie bilden daher nicht bloß die Grundlage jeder Diskussion über sein Gotenbild, sondern bieten zugleich auch den besten Zugang zu Malchos als Geschichtsschreiber. Die Sequenz beginnt mit einer Gesandtschaft, die Strabo nach dem Ende der Usurpation des Basiliskos an Zenon schickte, nachdem er seine Stellung als Heermeister an Theoderich verloren hatte (F 11). ${ }^{127}$ Malchos referiert zunächst, was die Gesandten des Goten vorbrachten, und teilt dann mit, daß der Senat es für unmöglich erklärt habe, zwei Föderatenheere zu unterhalten. Es folgt eine Ansprache, die Zenon an seine Soldaten hielt, um sie gegen Strabo einzunehmen, und zwar teils in indirekter, teils in direkter Rede. Schließlich schildert Malchos, wie drei namentlich genannte Anhänger Strabos auf der Folter überführt, von Zenon aber begnadigt werden. Diese Milde erklärt Malchos damit, daß der Kaiser den Eindruck habe vermeiden wollen, er habe es auf Blutvergießen abgesehen. ${ }^{128}$

In einem Fragment, das sich auf einen späteren Zeitpunkt bezieht, aber nicht unmittelbar anschließt (F 14), geht es dann um ergebnislose Verhandlungen, die Zenon mit Strabo aufgenommen hatte, um die bestehende Feindschaft mit diesem zu beenden. Zenons Initiative wird erneut durch ein rationales Kalkül motiviert: Der Kaiser habe bemerkt, daß die Position Theoderichs immer schwächer geworden sei, während gleichzeitig Strabo immer mehr Stammesgruppen (Ethne) um sich geschart habe. Das Angebot Zenons, Strabo werde sein Erbteil erhalten, wenn er seinen Sohn als Geisel stelle und als Privatmann friedlich auf seinem Besitz bleibe, wird ebenso wie

126 F 9, Z. 1-10: Zenons Klage, daß der Mensch bloß ein Spielzeug in der Hand Gottes sei; vgl. F 8b = ELR 5: Rest der Klagerede eines Verbannten. Im Suda-Artikel (T 1)

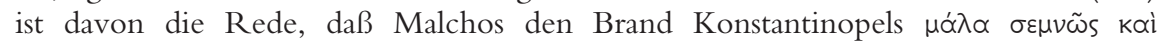
траү

127 Vgl. zum folgenden etwa Martin (s. Anm. 38), 19 ff.; H. Wolfram, Die Goten. Von den Anfängen bis zur Mitte des 6. Jahrhunderts, München ${ }^{3} 1990,259-278$; P. Heather, Goths and Romans 332-489, Oxford 1991, 225-308; A. Schwarcz, Die Goten in Pannonien und auf dem Balkan nach dem Ende des Hunnenreiches bis zum Italienzug Theoderichs des Großen, MIÖG 100, 1992, 50-83. Um Verwechslungen $\mathrm{zu}$ vermeiden, wird Theoderich der Sohn des Triarius im folgenden stets mit seinem Beinamen Strabo bezeichnet, Theoderich der Sohn des Thiudimir, den Malchos wie alle oströmischen Quellen fälschlich Sohn des Valamir nennt, einfach als Theoderich.

128 F $11=$ ELG 4 . 
die abschlägige Antwort Strabos in indirekter Rede wiedergegeben. Daraufhin faßt man auf römischer Seite den Beschluß, gegen Strabo Krieg zu führen. ${ }^{129}$

Malchos schildert anschließend, wie Zenon Theoderich veranlaßte, an diesem Krieg teilzunehmen, indem er den Senat einen Eid schwören ließ, daß man niemals mit Strabo ein Abkommen schließen werde. Nachdem der Kaiser Theoderich dann auch noch versprochen hat, daß zwei kaiserliche Heere auf dem Vormarsch zu ihm stoßen würden, setzt Theoderich seine Leute gegen Strabo in Marsch. Malchos stellt in eigenem Namen fest, daß die von Zenon zugesagte Unterstützung ausgeblieben sei. Dieser Wortbruch Zenons bildet das beherrschende Thema dieses (F 15) und der beiden folgenden Fragmente. Malchos legt zunächst dar, wie es infolge dieses Wortbruchs zu einer Art Nichtangriffspakt der beiden Gotenführer gekommen sei. Dabei gestaltet er eine höchst effektvolle Szene, indem er Strabo Theoderich in einer direkten Rede kräftig die Leviten lesen läßt: Theoderich, der als Eidbrecher, verrückter Kindskopf und Verräter der Goten gescholten wird, begreife nämlich nicht, was die Römer tatsächlich im Schilde führten: Sie wollten, daß die Goten sich gegenseitig aufrieben, damit sie selbst am Ende die lachenden Dritten wären. Malchos hält fest, daß diese Rede Strabos im Lager Theoderichs auf große Zustimmung gestoßen sei, und gibt jenem Gelegenheit, seine Vorwürfe am nächsten Tag noch einmal in direkter Rede zu äußern. Nun kommt es auf Druck von Theoderichs Gefolgschaft tatsächlich zu einer Art Nichtangriffspakt, und beide Gotenführer schicken Gesandte an den Kaiser. ${ }^{130}$

Die folgenden Verhandlungen werden wiederum in indirekter Rede wiedergegeben, zunächst die Forderungen Theoderichs, dann die Strabos und schließlich die Antwort des Kaisers. Theoderich beklagt den Wortbruch Zenons, worauf dieser entgegnet, Theoderich selbst sei ein Verräter, und ihm zugleich hohe Geldzahlungen verspricht, falls er gegen Strabo kämpfe. Als Theoderich ablehnt, läßt Zenon zum Krieg rüsten, bläst den Feldzug aber schnell wieder ab. Malchos vermag in dieser Entscheidung nichts anderes zu sehen als einen Rückfall des Kaisers in seine angeborene Feigheit. ${ }^{131} \mathrm{Im}$ nächsten, erneut eng anschließenden Fragment (F 17) werden dann die Verhandlungen geschildert, die dazu führten, daß Strabo erneut die Stellung eines Heermeisters erlangte, während Theoderich aus diesem Amt entfernt wurde.

$129 \mathrm{~F} 14=\mathrm{ELR} 7$.

130 F $15=$ ELR 8. Zwischen F 14 und F 15 fehlt ein Stück, denn zu Beginn von F 15 hat Zenon den am Ende von F 14 erwarteten Entschluß, Illus mit dem Krieg gegen Theoderich zu beauftragen, revidiert.

131 F 16 = ELG 6. Obwohl F 16 nicht in derselben Sammlung überliefert ist wie F 15, ist der enge Zusammenhang offenkundig, da zu Beginn von F 16 auf das Abkommen zwischen Theoderich und Strabo verwiesen wird, das am Ende von F 15 geschlossen wird. 
Wieder kommen beide Seiten in indirekter Rede zu Wort; die Vertragsbedingungen werden präzise und detailliert wiedergegeben. ${ }^{132}$

Das mit Abstand längste Fragment (F 18) setzt diese Situation voraus. ${ }^{133}$ Malchos schildert, wie Theoderich, außer sich vor Wut über das, was ihm widerfahren ist, Stobi verwüstet und Thessaloniki bedroht. Daraufhin wirft Zenon das Steuer erneut herum und knüpft wieder Verhandlungen mit Theoderich an. Malchos motiviert dies mit der Feststellung, Zenon habe gesehen, daß niemand bereit war, gegen Theoderich zu kämpfen. Die folgenden Verhandlungen hat Malchos mit einem großen Reichtum an topographischen und prosopographischen Details dargestellt; auch kleine Orte werden beim Namen genannt und Geländemerkmale genau beschrieben. Hinzu kommen nicht weniger als fünf direkte und indirekte Reden, die zwischen Theoderich und Gesandten des Kaisers gewechselt werden.

Die erste dieser Reden wird von zwei Gesandten gehalten, die Theoderich im Namen Zenons auffordern, er möge doch erneut mit dem Kaiser verhandeln; sie halten Theoderich vor, er sei undankbar gegenüber dem Kaiser, der ihn mit Ehren überhäuft und ihm das Kommando über die größten Truppenteile anvertraut habe, ohne ihm als Barbaren irgendwie zu mißtrauen. ${ }^{134}$ Theoderich entspricht dieser Bitte, fordert aber, daß der Kaiser einen bevollmächtigten Gesandten zu ihm schicke. Tatsächlich erteilt Zenon daraufhin dem patricius und ehemaligen Stadtpräfekten Adamantius den Auftrag, er solle Theoderich Land auf dem Gebiet der Stadt Pautalia zuweisen. Malchos stellt hier Insider-Wissen zur Schau: Er referiert nicht bloß die Instruktionen, die Adamantius von Zenon erhielt, sondern auch die Motive, die der Kaiser mit der Ansiedlung Theoderichs in Pautalia verfolgte: Von dieser Stelle aus könne Theoderich Strabo kontrollieren, aber auch selbst von den thrakischen und illyrischen Truppen in die Zange genommen werden. ${ }^{135}$

132 F $17=$ ELR 9. F 17 scheint direkt an F 16 anzuschließen, denn F 17 setzt mit der Auflösung des Heeres durch Zenon ein, die am Ende von F 16 geschildert wird.

133 Das Fragment ist in den „Excerpta de legationibus Romanorum“ am Anfang der Reihe überliefert, wo es aber nicht paßt, weil es Ereignisse voraussetzt, die in F 15 geschildert werden. Karl Müller hat vorgeschlagen, es nach F 17 zu plazieren. Dafür spricht eine Reihe von Gründen: Zu Beginn von F 18 ist von großen Verlusten Theoderichs die Rede, wie sie in F 17 geschildert werden. In den Verhandlungen mit Adamantius fordert Theoderich das Heermeisteramt zurück, während in F 17 erzählt wird, wie er es verlor. Zu Beginn von F 18 befindet sich Theoderich in der Gegend von Stobi, in F 17 im Rhodope-Gebirge, also auf dem Weg dorthin. Errington (s. Anm. 49), 8587 möchte F 18 dagegen vor F 17 plazieren; welche Schwierigkeiten daraus resultieren, zeigt Blockley (s. Anm. 49), 152-153.

134 F $18=$ ELR 1, Z. 29-41. Die Redner sind Artemidorus, der später mit Theoderich nach Italien zog und 509-510 Stadtpräfekt in Rom war (PLRE II Artemidorus 3), und Phocas, der nur hier bezeugt ist und Theoderich zuvor als Sekretär gedient hatte.

135 F $18=$ ELR 1, Z. $55-70$. 
Tatsächlich ist der folgende Bericht über die Mission des Adamantius so detailliert, daß er direkt oder indirekt auf diesen selbst zurückgehen muß. ${ }^{136}$ Malchos erzählt zunächst, wie es Theoderich mit Hilfe des Goten Sidimund gelingt, sich der Stadt Epidamnos zu bemächtigen. Genauso umständlich wird berichtet, welche Mühe es Adamantius kostete, überhaupt in Verhandlungen mit ihm zu treten, weil der Heermeister Sabinianus sich weigerte, den erforderlichen Sicherheitseid zu leisten. Der Zivilist gelangt schließlich mit einer Eskorte von 200 Soldaten auf unwegsamen Pfaden nach Epirus, wo er in einem Gespräch unter vier Augen auf Theoderich trifft.

Malchos hat die Szene breit ausgemalt. Zuerst kommt der Gote zu Wort und zwar in direkter Rede: Er versichert, er sei entschlossen gewesen, in Skythien, worunter wohl die gleichnamige Provinz zu verstehen ist, zu bleiben, und habe Thrakien nur auf Aufforderung der Römer betreten; er beklagt sich, daß die militärische und finanzielle Unterstützung, die man ihm versprochen habe, ausgeblieben sei, und erhebt den Vorwurf, die kaiserlichen Scouts hätten ihn absichtlich in eine Falle gelockt. ${ }^{137}$

Wenn Adamantius anschließend Gelegenheit erhält, die Position Zenons darzulegen, so dient dies nicht der Relativierung der Ausführungen Theoderichs, denn Malchos erklärt in eigenem Namen, daß er die Vorwürfe des Goten für berechtigt hält, und wiederholt dieses Urteil sogar noch einmal, ${ }^{138}$ bevor er die Rede des Adamantius referiert. Die Gegenrede des kaiserlichen Gesandten bringt die Verhandlungen voran, ohne die Vorwürfe des Goten zu widerlegen: Adamantius erinnert Theoderich noch einmal an die Auszeichnungen und Geschenke, mit denen ihn der Kaiser überhäuft habe, und ermahnt ihn, dem Kaiser wie seinem Vater zu begegnen. ${ }^{139}$ Er habe die während eines Gesandtenaustauschs geltende Waffenruhe gebrochen und könne im übrigen froh sein, daß die Römer sein Heer nicht vernichtet hätten, obwohl sie dazu Gelegenheit gehabt hätten. Nun aber solle er Epirus räumen und in die Provinz Dardania kommen, wo er viel gutes Land finden werde, um sein Heer zu ernähren. ${ }^{140}$

136 So bereits W. Barth, Kaiser Zeno, Diss. Basel 1894, 68 Anm. 1.

137 F $18=$ ELR 1, Z. 202-218.

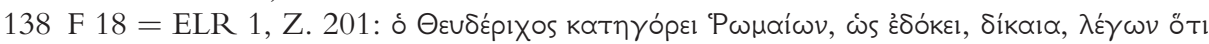

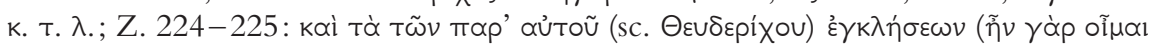

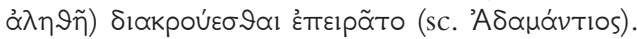

139 Hier ist wohl auf die Adoption Theoderichs als Waffensohn Zenons angespielt: Coll. Avell. 114, 1; Cass. Var. 8, 1, 3; Jord. Get. 289 mit D. Claude, Zur Begründung familiärer Beziehungen zwischen dem Kaiser und barbarischen Herrschern, in: E. K. Chrysos/A. Schwarcz (Hgg.), Das Reich und die Barbaren, Wien - Köln 1989, $25-$ 56, hier: $28-31$.

$140 \mathrm{~F} 18=\mathrm{ELR}$ 1, Z. 219-240. 
Darauf erteilt Malchos noch einmal Theoderich das Wort. ${ }^{141}$ Der erklärt, er sei grundsätzlich bereit, auf das Angebot des Kaisers einzugehen, könne sein Heer in diesem Winter aber unmöglich einen so weiten Weg führen, und stellt dann seine Bedingungen für die Ansiedlung in der Provinz Dardania: Wenn der Troß und die Invaliden in einer Stadt nach Zenons Wahl überwintern dürften, werde er sogleich mit 6000 Mann nach Thrakien ziehen, um gemeinsam mit den Truppen des Kaisers alle dort ansässigen Goten zu vernichten. Voraussetzung dafür sei allerdings, daß er zum Heermeister ernannt und in Konstantinopel aufgenommen werde, wo er nach römischer Art leben wolle. Als Alternative komme nur in Frage, daß der Kaiser ihn beauftrage, Nepos wieder als Kaiser nach Italien zurückzuführen. Adamantius sagt schließlich zu, diese Vorschläge dem Kaiser zu unterbreiten, doch zum Abschluß eines Vertrages kommt es nicht. Inzwischen hat nämlich der Heermeister Sabinianus Theoderichs Troß angegriffen und dabei einen Sieg errungen. Er verfaßt darüber einen Bericht, der nach Malchos' Meinung ziemlich übertrieben war, und rät dem Kaiser zu einem gewaltsamen Vorgehen gegen Theoderich. Auf diesen Bericht hin, so Malchos, sei Zenon zu der Auffassung gelangt, daß Krieg besser sei als ein schändlicher Friede, und habe seine Politik ein weiteres Mal geändert. Adamantius erhält ein Belobigungsschreiben und wird entlassen. ${ }^{142}$

Malchos ist es in diesem Teil seines Geschichtswerks gelungen, verschiedene Handlungsfäden so zu verknüpfen, daß der Leser dem komplizierten Geschehen mühelos zu folgen vermag; das zeugt von seinem Talent als Erzähler. Die Darstellung trägt über weite Strecken den Charakter eines Berichts, da der Autor das Geschehen nur selten in eigenem Namen kommentiert. Indem er den Akteuren jedoch immer wieder bestimmte Motive zuschreibt, legt er dem Leser in der Regel eine bestimmte Interpretation des Geschehens nahe. Die Erzählperspektive wechselt dabei häufig hin und her, so daß der Leser das Geschehen von mehreren Seiten zu sehen bekommt. Es liegt auf der Hand, daß die vielen Reden wesentlich zu dieser Multiperspektivität der Darstellung beitragen. Wie aber steht der Autor zu den Auffassungen, die seine Redner vertreten? Will Malchos einfach wiedergeben, was sie gesagt haben? Legt er den Rednern seine eigenen Gedanken in den Mund? Oder läßt er sie vorbringen, was ihm für eine Person oder Situation angemessen erscheint? Mit besonderer Dringlichkeit stellen sich diese Fragen für die Reden, die zwischen dem Kaiser und seinen Vertretern einerseits und den beiden Gotenführern andererseits gewechselt werden.

Was die Reden angeht, in denen Strabo Theoderich als Verräter an seiner gotischen Verwandtschaft und als Dummkopf attackiert, der nicht begreife,

141 F $18=$ ELR 1, Z. 241-260.

142 F $18=$ ELR 1, Z. 294-320, bes. Z. 301-309. 
wie die Römer die Goten gegeneinander ausspielten, darf man sicher sein, daß es Malchos nicht um eine Entlarvung der römischen Politik ging. Malchos war beileibe kein Gotenfreund. Er nennt die Goten und ihre Anführer wiederholt Barbaren, und dies war durchaus pejorativ gemeint. Auf die traditionelle Barbarentopik wird mehrfach rekurriert: auf die Treulosigkeit des Barbaren ${ }^{143}$ ebenso wie auf seine Geldgier ${ }^{144}$. Sie ist für Malchos auch kein bloßes rhetorisches Versatzstück, sondern wird zur Motivierung von Handlungen verwendet: Der föderierte Gote Sidimundus spielt Theoderich Epidamnos durch einen Trick in die Hände, weil er, so Malchos, als Barbar der Meinung gewesen sei, besser mit Barbaren leben zu können als mit Römern. ${ }^{145}$ Malchos stellt eindringlich dar, wie die Provinzialen unter den Heeren der beiden Gotenführer zu leiden haben. Die Kunde, die Goten kämen, löst überall Furcht, oftmals panikartige Flucht, manchmal auch Aufruhr aus. ${ }^{146}$ Die Einwohner von Arkadioupolis werden von Strabo ausgehungert und müssen sich ergeben; die von Philippi können froh sein, daß nur die Gegend vor der Stadt verbrannt wird. ${ }^{147}$ Von Theoderich erzählt Malchos, er habe auf seinem Zug durch Thrakien die Bauern ruiniert, indem er das Vieh raubte, mordete und plünderte. ${ }^{148}$ Aus Wut über Verluste, die ihm römische Truppen zufügen, so Malchos, verbrennt und tötet der Gote schonungslos alles, worauf er stößt; er verwüstet Stobi und bringt alle Soldaten um, die ihm Widerstand leisten. ${ }^{149}$ Die Einwohner des makedonischen Herakleia verschont Theoderich zunächst, weil sie ihm große Geschenke machen und sich freiwillig in ein Kastell zurückziehen; als sie sich jedoch weigern, ihn mit Proviant zu beliefern, weil sie selbst nichts mehr haben, wird er zornig und brennt die menschenleere Stadt bei seinem Abzug nieder. ${ }^{150}$

Wenn Malchos Strabo Theoderich daher vor dem Doppelspiel der Römer warnen läßt, so will er offenbar demonstrieren, daß die Schaukelpolitik Zenons leicht durchschaubar war und deshalb auch beinahe das Gegenteil von dem bewirkt hätte, was sie bezweckte: den Zusammenschluß der beiden gotischen Kriegergruppen auf dem Balkan. Um ein Haar hätte Zenons Lavieren zum Untergang Konstantinopels geführt. Malchos war der Auffassung daran lassen die auktorialen Kommentare zur Gesandtschaft des Adamantius keinen Zweifel -, daß Theoderich sich mit Recht über den Wortbruch Ze-

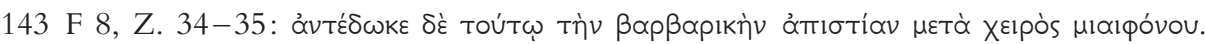

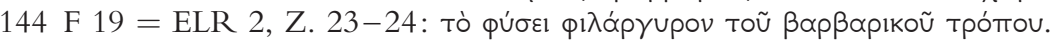

145 F $18=$ ELR 1, Z. 88-90.

146 Thessaloniki: F 18 = ELR 1, Z. 6-23; Epidamnos: F 18 = ELR 1, Z. 90-102;

Herakleia in Makedonien: F $18=$ ELR 1, Z. 112-117.

147 F 2 = ELG 2.

148 F $17=$ ELR 9, Z. 4-8.

149 F $18=$ ELR 1 , Z. $1-6$.

150 F $18=$ ELR 1, Z. 46-51; Z. 112-119. 
nons beklagte. Die Gesandtschaft des Adamantius bot ihm Gelegenheit darzustellen, wie schwankend und unberechenbar die Außenpolitik des Kaisers war, der aus seiner Sicht einerseits zu feige war, um eine militärische Lösung $\mathrm{zu}$ erreichen, andererseits aber abhängig von schlechten Ratgebern wie Sabinianus, die ihn über die wahre Sachlage täuschten. ${ }^{151}$ Die Reden, die Malchos in diesem Zusammenhang mitteilt, erfüllen dabei mehrere Funktionen: Zum einen betonen sie die Treulosigkeit Zenons, indem sie den Vorwurf, er habe Theoderich in eine Falle gelockt, zum Gegenstand einer ausführlichen Erörterung machen, deren Ergebnis von vornherein feststeht. Zum anderen charakterisieren sie die beiden Protagonisten Theoderich und Adamantius: Adamantius ist der loyale Diener seines Kaisers, der seinen Auftrag mit Geschick erfüllt, Theoderich der nicht ohne Grund verärgerte Gotenkönig, der nichts lieber will, als dem Kaiser zu dienen, vorausgesetzt, daß dieser seine Versprechungen auch einhält.

Während Malchos in hohem Maße personalisiert und moralisiert, wenn es um Zenon geht, berücksichtigt er strukturelle Determinanten politischer Entscheidungen viel stärker, wenn er die beiden Theoderiche in den Blick nimmt. Vor allem hebt er wiederholt hervor, daß die beiden gotischen Heerführer in ihren Entscheidungen nicht frei, sondern von ihrer Gefolgschaft abhängig waren. Malchos macht deutlich, daß diese Abhängigkeit in den Verhandlungen mit Zenon mehrfach thematisiert wurde: So läßt er Strabo Zenons Angebot, er werde sein Vermögen zurückerhalten, wenn er sich verpflichte, als Privatmann auf seinem Besitz zu bleiben, mit dem Argument zurückweisen, er könne sich nicht mehr ins Privatleben zurückziehen, weil er eine große Gefolgschaft zu ernähren habe und daher entweder siegen oder untergehen müsse. ${ }^{152}$ Als Strabo mit seinem Heer vor Konstantinopel erscheint und Zenon ihm erklärt, er werde nicht mehr gebraucht, erwidert Strabo, er würde ja gerne gehorchen, aber seine Soldaten seien nicht bereit, so einfach umzukehren. ${ }^{153}$ Theoderich schwört einen Eid, daß er seine Leute nicht gegen ihren Willen im tiefen Winter von Epirus Nova nach Dardania führen könne, ${ }^{154}$ und begründet die Forderung, ihm und seinen Leuten Land zu geben, mit dem Argument, andernfalls könne er sie nicht daran hindern, sich zu nehmen,

151 Auch hier richtet sich die Kritik gegen einen Toten, denn Sabinianus war seit 481 nicht mehr unter den Lebenden: PLRE II Sabinianus 4. Sein Ruf war jedoch keineswegs überall so schlecht, wie es nach Malchos' Bericht scheinen könnte: Marcellinus Comes lobt ihn in den höchsten Tönen (ad a. 479: disciplinae militaris ita optimus institutor coercitorque fuit ut priscis Romanorum ducibus comparetur) und bemerkt zu seinem Tod (ad a. 481), er wäre in der Lage gewesen, dem erschöpften Staat wirksame Hilfe zu leisten, wenn er länger gelebt hätte.

152 F $14=$ ELR 7, Z. 14-18.

153 F $19=$ ELR 2, Z. 12-15.

154 F $18=$ ELR 1, Z. 241-245. 
was sie bräuchten. ${ }^{155}$ Bei diesen Äußerungen handelt es sich für Malchos keineswegs um bloße Vorwände. Er erwähnt mehrfach, daß die Goten selbst Hunger litten, ${ }^{156}$ und führt dem Leser eindringlich vor Augen, wie Theoderich von seinen eigenen Leuten gezwungen wird, den Kampf gegen Strabo einzustellen. ${ }^{157}$

Die Abhängigkeit von einer Gefolgschaft, die von ihrem Anführer versorgt werden will, ist ein strukturelles Problem, das Malchos bei beiden gotischen Anführern konstatiert. Dennoch hat er sie durchaus unterschiedlich gezeichnet und beurteilt. An verschiedenen Stellen wird deutlich, daß er Strabo für gefährlicher hält als Theoderich, dem er die grundsätzliche Bereitschaft zuschreibt, sich dem Kaiser zu unterstellen und ins Reich zu integrieren. Auch wenn sich nicht mehr sicher rekonstruieren läßt, wie Malchos die Kooperation Strabos mit dem von ihm abgelehnten Usurpator Basiliskos beurteilt hat, ${ }^{158}$ steht außer Zweifel, daß er ein in den Augen des Malchos unverzeihliches Verbrechen plante, als er den Usurpator Marcian gegen Zenon unterstützen wollte. Für Malchos war dies ein Angriff auf den Kaiser, vor allem aber auf „die Stadt“, die dadurch in allerhöchste Gefahr geriet. Auch Theoderich ist bei Malchos ein Barbar und zu jeder Grausamkeit fähig, wenn er in Wut gerät. Aber die Wut Theoderichs auf Zenon ist nach Malchos' Darstellung zumindest verständlich, da der Kaiser ihn hintergangen hat. ${ }^{159}$ Zudem wird betont, daß Theoderich seine Leute zwar nicht habe hindern können, Lebensmittel zu requirieren, aber doch vom Morden und Brennen abgehalten habe, solange er auf eine Verständigung mit dem Kaiser hoffte. ${ }^{160}$

Vor allem aber zeigt Theoderich bei Malchos im Gegensatz zu Strabo großen Respekt vor dem Kaiser, dem römischen Reich und seiner Hauptstadt Konstantinopel. Bei den Verhandlungen, die der Gesandte Adamantius für Zenon führt, läßt Malchos Theoderich das Angebot machen, alle Goten in Thrakien zu vernichten, falls er ,zum Heermeister bestellt und in die Stadt aufgenommen werde, um auf römische Art Bürger zu sein. Er sei aber auch bereit, wenn der Kaiser den Befehl erteile, nach Dalmatien abzuziehen, um

155 F $16=$ ELG 6, Z. 6-13.

156 F $2=$ ELG 2, Z. 24; F $18=$ ELR 1, Z. 44-45.

157 F $15=$ ELR 8, Z. 64-74.

158 In F 8, Z. 12-14 und F $11=$ ELG 4, Z. 23-25 wird auf sie verwiesen. Wenn Phot. Cod. $78=$ T 2, Z. 13-15 auf diese Ereignisse zu beziehen ist, hat Malchos Strabo Rebellion gegen den regierenden Kaiser vorgeworfen.

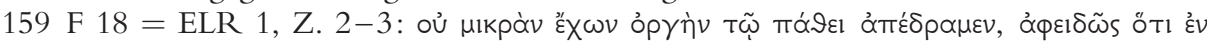

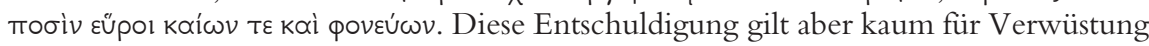
des makedonischen Herakleia, nachdem die Bewohner erklärt hatten, sie könnten ihm keine Lebensmittel liefern, weil sie selbst keine mehr hätten: F 18 = ELR 1, Z. $117-$

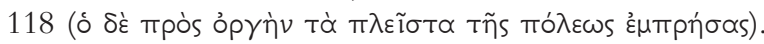

$160 \mathrm{~F} 18=\mathrm{ELR} 1$, Z. 41-51. 
Nepos wieder einzusetzen. “161 Diese Bereitschaft zur Integration läßt Strabo bei Malchos nirgendwo erkennen. Theoderich geht es seiner Darstellung zufolge auch nicht in erster Linie um Subsidien, sondern um Land für seine Gefolgschaft. Als Theoderich und Strabo in der Zeit ihres „Nichtangriffspaktes" Gesandte an Zenon schicken, fordert dieser das Heermeisteramt und Subsidien, jener aber Land, wo er seine Leute ernähren könne. ${ }^{162}$ Als man Theoderich die Ansiedlung auf dem Gebiet der Stadt Pautalia in der Provinz Dacia Mediterranea anbietet, lehnt er zwar ab mit dem Argument, daß er dort nichts gesät habe und folglich auch nichts ernten könne. ${ }^{163}$ Als man Theoderich später jedoch anbietet, sich in der im Südwesten angrenzenden Provinz Dardania niederzulassen, wo es viel gutes und herrenloses Land gebe, das er bebauen könne, um sein Heer zu ernähren, nimmt er an. ${ }^{164}$

Malchos hat das Dilemma, vor dem Zenon auf dem Balkan stand, klar beschrieben: Der Kaiser stand zwischen zwei gotischen Kriegergruppen, die im Vorfeld der Hauptstadt agierten. Zenons Versuch, die beiden gegeneinander auszuspielen, war für Malchos jedoch lediglich Ausdruck seiner Wankelmütigkeit, ein plan- und zielloses Hin- und Herlavieren, das die Gefahr heraufbeschwor, daß sich Strabo und Theoderich gegen Kaiser und Reich verbündeten. Es hatte zudem zur Folge, daß die Untertanen jedes Vertrauen in den Kaiser einbüßten und stets damit rechneten, den Goten geopfert zu werden, wie Malchos wiederholt hervorhebt. ${ }^{165}$ Malchos' Begeisterung für kriegstüchtige Herrscher deutet daraufhin, daß er sich gewünschte hätte, man hätte die beiden Theoderiche mit Gewalt zur Räson gebracht; bezeichnenderweise trifft er in eigenem Namen die Feststellung, die meisten Soldaten seien verärgert gewesen, als Zenon den geplanten Feldzug gegen Theoderichs Goten abblies, zumal sie zu schnell getrennt worden seien, um einen Anführer zu wählen, „der den Staat irgendwie aus der gegenwärtigen Schmach hätte herausführen können“. ${ }^{166}$ Wer dazu nicht fähig war, mußte seiner Ansicht

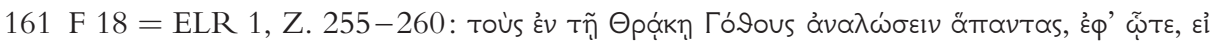

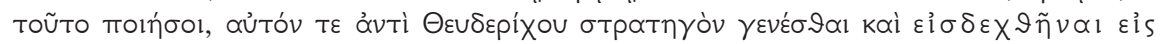

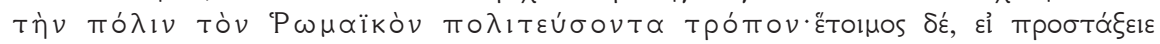

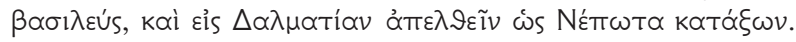

162 F $16=$ ELG 6, Z. 6-8. Gegenüber Sidimund erklärt Theoderich, er wolle sich der Provinz Epirus Nova und der Stadt Epidamnos bemächtigen, um dort an einem sicheren Ort bleiben und abwarten zu können, was ihm wiederfahren werde: F $18=$ ELR 1, Z. $85-88$.

163 F 18 = ELR 1, Z. 58-70. Weshalb Malchos Pautalia, eine Stadt in der Provinz Dacia

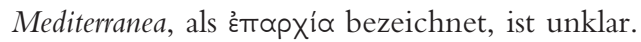

164 F $18=$ ELR 1, Z. 237-240; Z. 247-249.

165 F $18=$ ELR 1, Z. 6-23 (Thessaloniki); Z. 94-96 (Epidamnos).

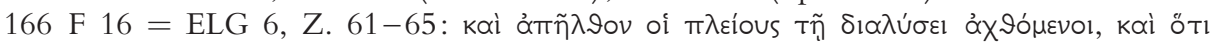

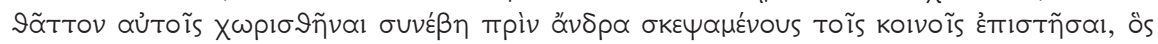

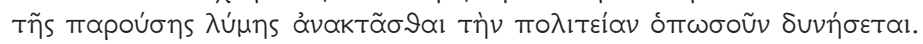


nach mit einem der beiden Gotenführer kooperieren. In diesem Fall wäre der Kaiser nach Ansicht des Malchos gut beraten gewesen, sich für Theoderich zu entscheiden. In seinem Urteil über Theoderich steht Malchos folglich Eustathios, der das Ansehen des Goten bei den Römern hervorhebt, viel näher als Candidus, für den Theoderich um kein Deut besser ist als Strabo, ${ }^{167}$ oder als Zacharias, der den gotischen König schlichtweg als Tyrannen bezeichnet. ${ }^{168}$ Vielleicht ist es daher durchaus bedeutsam, daß Malchos erwähnt, Theoderich habe Zenon schon im Jahre 480 angeboten, nach Dalmatien zu ziehen, um Nepos als Kaiser im Westen wieder einzusetzen. Auch hier wird dem Leser signalisiert, daß Theoderich bereit war, sich in den Dienst des Imperium Romanum zu stellen.

IV.

Der Sophist Malchos schrieb die Geschichte des oströmischen Reiches unter den Kaisern Leon und Zenon im Stile der klassischen griechischen Historiographie. Dabei benutzte er das gesamte literarische Instrumentarium, das ihm die Tradition profaner Geschichtsschreibung für die Verdeutlichung und Verlebendigung geschichtlicher Vorgänge zur Verfügung stellte: Fokalisierung und Dramatisierung, direkte und indirekte Reden. Aber auch die Kategorien, mit deren Hilfe er das Geschehen deutete, entstammen der Tradition profaner Geschichtsschreibung. Bei Malchos resultieren Handlungen fast immer aus immanenten Ursachen, in der Regel aus Charaktereigenschaften, die er den Akteuren zuschreibt, aber auch aus der rationalen Kalkulation von Machtinteressen und Erfolgschancen. Personalisierende Deutungen haben dabei ein klares Übergewicht; nur auf gotischer Seite werden strukturelle Determinanten individuellen Handelns mit in den Blick genommen.

167 Roberto (s. Anm. 24), 718-720 betont mit Recht die Unterschiede zwischen Eustathios und Candidus, rückt jedoch Malchos zu sehr in die Nähe des letzteren. Was die Einschätzung der gotischen Anführer angeht, gehen Malchos und Candidus weit auseinander.

168 Zach. Rhet. H. E. 6, 6: „In his days, one Theoderic, a tyrant had taken captives from Thrace and many other places, and had gone to Rome and subdued it, because Odoacer the Anti-Caesar there fled before to Ravenna a city of Italy. " Zum Begriff

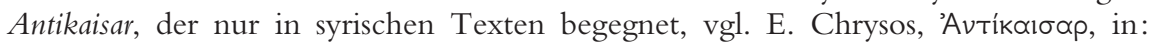
N. A. Stratos (Hg.), Byzantion. Tribute to A. N. Stratos, Bd. 1, Athen 1986, 73-82; Prostko-Prostynski (s. Anm. 13), 176. Der unbekannte Verfasser der um 569 veröffentlichten, fälschlich Zacharias Rhetor zugeschriebenen Kirchengeschichte legt ihn „Amalarich“ (= Theoderich) als Herrscher Italiens $(7,12)$ und Justinian als Mitregenten Justins I. $(9,1)$ bei. Jakob von Edessa $(† 708)$ dagegen verwendet ihn für Odovakar, während er Theoderich als Tyrannen bezeichnet: E. W. Brooks, The Chronological Canon of James of Edessa, ZDMG 53, 1899, 261-327, hier: 316 Nr. 166. 
Auf transzendente Ursachen hingegen rekurrierte Malchos offenbar selten und dann eher beiläufig. Die tödliche Krankheit des Thronfolgers Zenon deutete er als Strafe für dessen verkommenen Lebenswandel, die von Gott über ihn verhängt worden sei. ${ }^{169}$ Auch der Tod des Heermeisters Heraclius entsprach seiner Auffassung nach dem Willen Gottes, der in diesem Fall jedoch durch Menschen vollzogen wurde, die ihre eigenen und von Malchos auch benannten Ziele verfolgten. ${ }^{170}$ Diese indirekte Einflußnahme Gottes auf das geschichtliche Geschehen, die für das Geschichtsverständnis christlicher Chronisten von konstitutiver Bedeutung ist, ${ }^{171}$ spielte bei Malchos jedoch, soweit wir sehen, keine Rolle, wenn es um die Deutung politischer Weichenstellungen oder großer Ereigniszusammenhänge ging.

Völlig unberührt war Malchos von den eschatologischen Ängsten, die viele seiner Zeitgenossen quälten und den Autor der syrischen Chronik, die Josua Stylites zugeschrieben wird, zu einer eingehenden Auseinandersetzung veranlaßten. ${ }^{172}$ Die Entscheidung für die klassizistische Form der Geschichtsschreibung bedeutete eine Absage an das unter Christen verbreitete Bemühen, das Ende der Welt und damit der Geschichte zu berechnen. Diese Distanz gegenüber apokalyptischen Geschichtsdeutungen impliziert keine generelle Ablehnung des Christentums, wohl aber Distanz gegenüber dem universalen Geltungsanspruch theologischer Deutungsmuster, und zeugt daher von der Persistenz profaner Sinnkonzepte an der Schwelle vom 5. zum 6. Jahrhundert. Auch den tiefen Pessimismus seines heidnischen Zeitgenossen Zosimos, der in seinem Geschichtswerk zeigen wollte, daß die Vernachlässigung des Kultes der alten Götter der Grund sei, weshalb das Römische Reich in der Gegenwart vor dem Untergang stehe, ${ }^{173}$ hat Malchos offenkundig nicht geteilt, auch wenn

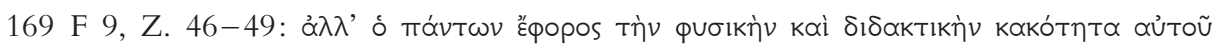

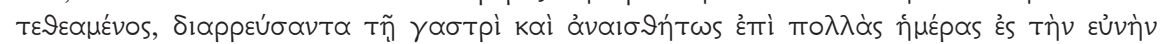

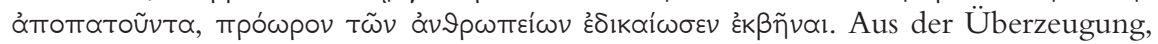
daß Leon einen qualvollen Tod verdient habe, erklärt sich wohl auch, weshalb Malchos ihn eingehend beschrieben hat (F 2d; Phot. Cod. $78=$ T 2, Z. 3-4).

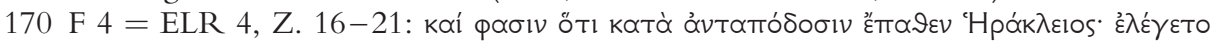

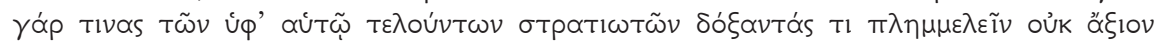

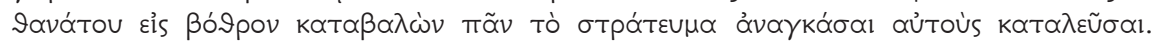

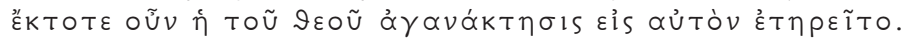

$171 \mathrm{Zu}$ dieser doppelten Rationalität im Geschichtsdenken des Josua Stylites vgl. Luther (s. Anm. 29), 245-255.

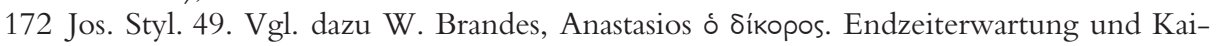
serkritik in Byzanz um 500 n. Chr., BZ 90, 1997, 24-63; M. Meier, Das andere Zeitalter Justinians. Kontingenzerfahrung und Kontingenzbewältigung im 6. Jahrhundert n. Chr. (Hypomnemata. Untersuchungen zur antiken Literatur und Geschichte 147), Göttingen 2003, 45-100, bes. 72-76.

173 Zos. 1, 57, 1; 58, 4; 3, 32, 6; 4, 21, 3; 59, 3; 5, 41, 7. Zur Interpretation vgl. Meier (s. Anm. 172), 55-62, der aufzeigt, daß Zosimos kein stumpfsinniger Kompilator ist, 
er nicht unbedingt geglaubt haben dürfte, daß mit dem Regierungsantritt des Anastasius ein neues goldenes Zeitalter angebrochen sei. Gewiß, Malchos legt den Soldaten Zenons die Aussage in den Mund, ihre eigene Weichlichkeit habe „die Städte und die gesamte römische Macht zugrunde gerichtet“, da alle sich nach Gutdünken davon abschnitten, was sie wollten. ${ }^{174}$ Aber diese Diagnose gilt bloß retrospektiv und entspricht dem Bild, das man unter Anastasius von der Außenpolitik Zenons zu zeichnen pflegte; sie zeugt daher weder von Opposition noch von Resignation oder gar Verzweiflung.

Profaner Natur waren auch die Kriterien, an denen Malchos das Verhalten von Kaisern maß. Wie viele spätrömische Geschichtsschreiber machte er sein Urteil davon abhängig, ob sie Besitz und Leben ihrer Untertanen respektierten und garantierten. Niedrige Steuern und Rechtssicherheit waren für ihn unverzichtbare Merkmale eines guten Regiments. Der gute Kaiser sollte seine Untertanen aber nicht bloß schonend behandeln, sondern auch vor äußeren Feinden schützen; deshalb sollte er den Barbaren Furcht einflößen und selbst in den Krieg ziehen. Die Stellung zu Glaubensfragen scheint für Malchos' Urteil über die Kaiser hingegen unerheblich gewesen zu sein, und kirchliche Belange spielten in seinem Werk offenbar nur eine sehr geringe Rolle. Malchos unterscheidet sich in dieser Hinsicht nicht bloß von Zacharias, der als Verfasser einer Kirchengeschichte die Religionspolitik der Kaiser fokussierte, sondern auch von Candidus, der als Anhänger der Synode von Chalkedon Reichsgeschichte schrieb und entsprechend beurteilte. Von dieser Vermischung der Traditionen profaner und kirchlicher Geschichtsschreibung, die in den Werken eines Theophylakt und Euagrios ihren Höhepunkt finden sollte,${ }^{175}$ ist Malchos weit entfernt.

Daß Malchos dem barbarisierten Militär seiner Zeit grundsätzlich mit Argwohn und Mißtrauen gegenüberstand, paßt zu seiner Stellung als gebildeter Repräsentant der zivilen Eliten. Er sah in den Soldaten eine potentielle

sondern eine durchaus originelle Deutung der römischen Geschichte vertritt, aber aufgrund von F 16 = ELG 6 zu Unrecht annimmt (71), Malchos habe das Westreich als untergegangen betrachtet und sei daher wie Zosimos ein Zeuge für das Krisenbewußtsein heidnischer Intellektueller um 500. Diese Interpretation traktiert den Text, als ob Kritik am regierenden Kaiser geübt würde, während es sich in Wahrheit um rückwärtsgewandte Polemik handelt (in diesem Sinne auch A. Goltz in seiner Rezension (H-Soz-u-Kult, 06.12.2004, http://hsozkult.geschichte.hu-berlin.de/rezensionen/2004-4-160).

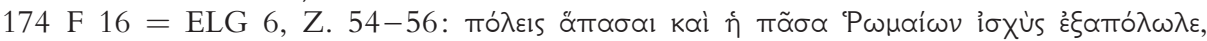

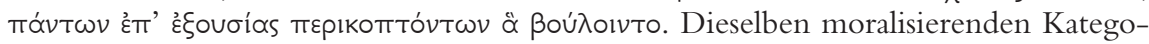
rien, die Malchos' Kritik an Leon und Zenon bestimmen, liegen auch seiner Diagnose des Vandalenreiches zugrunde: F $13=$ ELG 5, Z. 18-23. Da es sich um menschliches Versagen handelt, kann es auch wieder besser werden.

175 M. Meier, Prokop, Agathias, die Pest und das „Ende“ der antiken Historiographie. Naturkatastrophen und Geschichtsschreibung in der ausgehenden Spätantike, HZ 278, 2004, 281-310. 
Bedrohung, vor allem aber eine schwere finanzielle Belastung. Ganz unerträglich war dem Historiographen die Existenz konkurrierender Kriegerverbände, die den Kaiser mit erpresserischen Forderungen konfrontierten. Malchos hatte an der Regierung Kaiser Zenons vieles auszusetzen: im Inneren Verschwendung, Steuerdruck und Verkauf von Ämtern zu überhöhten Preisen an ungeeignete Personen, nach außen den Mangel an Konstanz und Stärke. Diese Vorwürfe liegen auf der Linie dessen, was man unter Anastasius allgemein an dessen Vorgänger bemängelte. Sie waren damals so geläufig, daß selbst der Verfasser der Lebensbeschreibung des Styliten Daniel, der in Zenon einen Verehrer seines Heiligen und Beschützer der Orthodoxie sieht, dem Kaiser kurz vor seinem Tod die Ermahnung zuteil werden läßt, er solle sich vor Habgier und ungerechten Anklagen hüten und seinen Feinden vergeben. ${ }^{176}$ Auch was die Isaurerfrage angeht, war Malchos keineswegs oppositionell eingestellt - da er in den Isaurern eine Gefahr für Konstantinopel sah, dürfte er ihre Vertreibung aus der Hauptstadt lebhaft begrüßt haben.

Bei aller Kritik war Zenon für Malchos - im Gegensatz zu Leon - kein durch und durch schlechter Mensch, wenngleich feige und unwissend. Zenon war seiner Auffassung nach vor allem schwach. Für die negativen Seiten der Herrschaft Zenons waren daher in erster Linie dessen Berater und Freunde verantwortlich, die Malchos heftig attackiert hat. Dieses Deutungsmuster unterscheidet Malchos von Eustathios, der die Grausamkeit und Treulosigkeit des Kaisers betonte, entsprach hingegen der taktvoll verhüllenden Art und Weise, wie man zur Zeit des Anastasius in der Öffentlichkeit über Zenon zu sprechen pflegte.

Die Vorstellung, daß Zenon vor allem schwach und wankelmütig gewesen sei, bestimmte auch Malchos' Darstellung der Beziehungen zwischen dem Kaiser und den gotischen Kriegergruppen auf dem Balkan. Für ihn war das Lavieren zwischen den beiden Theoderichen ein gefährlicher Fehler, der beinahe dazu geführt hätte, daß sich die beiden gegen Kaiser und Reich zusammengeschlossen hätten. $\mathrm{Da}$ es dazu dann doch nicht kam, war nicht Zenons Verdienst, sondern lag vor allem daran, daß die Rivalität unter den beiden Gotenfuihrern zu groß war. Malchos machte deutlich, daß sie in ihrem Handeln von den Wünschen ihrer Gefolgschaften abhängig waren, und gelangte insofern über die personalisierende Betrachtungsweise hinaus, die seine Sicht der Kaiser bestimmt. Gleichwohl hat er die beiden Theoderiche nicht völlig schematisch gezeichnet. Insbesondere deutet er mehrfach an, daß Theoderich in höherem Maße an einer Integration in das Reich gelegen war

176 V.Dan. 91. Vgl. zu diesem wenig studierten Text neben Brandes (s. Anm. 114), 417421 vor allem R. Lane Fox, The Life of Daniel, in: M. J. Edwards/S. Swain (Hgg.), Portraits. Biographical Representation in the Greek and Latin Literature of the Roman Empire, Oxford 1997, 175-225. 
als seinem Widersacher. Bezeichnenderweise bekommt der Gote Gelegenheit, den Wunsch zu äußern, er wolle als römischer Bürger in Konstantinopel leben. Auch in diesem Punkt entfernte sich Malchos nicht weit von dem, was zur Abfassungszeit opportun war, denn als er schrieb, war Strabo lange tot, und sein Rivale herrschte an Kaisers Statt in Italien. Gleichwohl war seine Sicht Theoderichs auch nicht konkurrenzlos: Candidus und Zacharias sahen den gotischen König als grausamen Barbaren, ja als Tyrannen. Als man unter Anastasius' Nachfolger Iustinus darüber nachzudenken begann, wie man die Amalerherrschaft in Italien eines Tages wieder beenden könne, hat Marcellinus Comes Theoderich als gewalttätigen und unersättlichen Barbaren gezeichnet, der weite Teile Griechenlands verwüstet habe, bis er mit seinen Leuten nach Italien gezogen sei, wo er Odovakar durch Meineid in seine Gewalt gebracht und getötet habe. ${ }^{177}$ Malchos dagegen scheint der Auffassung gewesen zu sein, daß dem Reich viel Ungemach erspart geblieben wäre, wenn Zenon sich frühzeitig zu einer konsequenten Kooperation mit Theoderich hätte durchringen können.

177 Marc. Com. ad a. 479, 2; 482, 2; 483; 487; 488, 2; 489. Vgl. dazu A. Goltz, Marcellinus Comes und das „Ende“ desWeströmischen Reiches, Electrum 13, 2007, $39-$ 59 , bes. $48 \mathrm{ff}$. 